Contract No. and Disclaimer:

This manuscript has been authored by Savannah River Nuclear Solutions, LLC under Contract No. DE-AC09-08SR22470 with the U.S. Department of Energy. The United States Government retains and the publisher, by accepting this article for publication, acknowledges that the United States Government retains a non-exclusive, paid-up, irrevocable, worldwide license to publish or reproduce the published form of this work, or allow others to do so, for United States Government purposes. 


\title{
Acceptability envelope for metal hydride-based hydrogen storage
}

\section{systems}

\author{
Claudio Corgnale, Bruce J. Hardy ${ }^{1}$, David A. Tamburello, Stephen L. Garrison, \\ Donald L. Anton
}

Savannah River National Laboratory, Aiken, SC 29808, USA

\begin{abstract}
The design and evaluation of media based hydrogen storage systems requires the use of detailed numerical models and experimental studies, with significant amount of time and monetary investment. Thus a scoping tool, referred to as the Acceptability Envelope, was developed to screen preliminary candidate media and storage vessel designs, identifying the range of chemical, physical and geometrical parameters for the coupled media and storage vessel system that allow it to meet performance targets. The model which underpins the analysis allows simplifying the storage system, thus resulting in one input-one output scheme, by grouping of selected quantities.

Two cases have been analyzed and results are presented here. In the first application the DOE technical targets (Year 2010, Year 2015 and Ultimate) are used to determine the range of parameters required for the metal hydride media and storage vessel. In the second case the most promising metal hydrides available are compared,

\footnotetext{
${ }^{1}$ Tel: +1 803646 4082; Email address: bruce.hardy@srnl.doe.gov
} 
highlighting the potential of storage systems, utilizing them, to achieve $40 \%$ of the 2010 DOE technical target. Results show that systems based on Li-Mg media have the best potential to attain these performance targets.

\section{Introduction}

Hydrogen stored onboard a vehicle must be stored compactly and the mass of media, vessel, heat transfer apparatus, etc. must be sufficiently low so as to make it practical as an alternative fuel. In order to increase its volumetric energy density (which is on the order of one third that of methane, at normal conditions), hydrogen can be stored as a compressed gas, as a liquid or bound to a media that is capable of releasing the gas in a nearly reversible manner. Compression requires high pressures, on the order of 350700 bar or higher, requiring a great amount of work [1,2]. In the case of liquefaction, high gravimetric densities are achieved at low pressures, but the process is even more expensive than pure compression due to the electric power required to cool the hydrogen to sufficiently low temperatures (approximately $20 \mathrm{~K}$ at 1 bar) $[1,3]$ and the issue of continual boil with its reduction in efficiency must be addressed. The use of a media for storage permits hydrogen to be stored at relatively low pressures compared to compressed hydrogen storage, and requires far less electric power consumption than needed for liquefaction.

Media used for vehicular hydrogen storage is conventionally divided into three classes: 
1. Chemical hydrides that would be refueled off board a vehicle,

2. Adsorbents that require low (cryogenic) temperatures to retain an adequate amount of hydrogen, and may be refueled on board,

3. Metal hydrides that undergo chemical reactions during charge and discharge and may be refueled on board.

The behavior of the various storage media during charging and discharging of hydrogen is quite complex, involving chemical kinetics or thermodynamics coupled with mass, momentum and thermal transport processes. Moreover, there is significant variation in the behavior among different storage media, even within a given class, requiring storage vessel designs that are medium specific. The performance of a storage system, therefore, is a coupling between the medium and the vessel. The evaluation and design of such systems require the use of detailed numerical models and experimental studies. As these efforts require a significant amount of time, it is important to have an efficient numerical tool able to identify coupled media and storage system designs that are most likely to meet target performance requirements, prior to engaging in more detailed evaluations [4].

A large number of detailed numerical models have been developed to study and to optimize different media-based storage systems [5-19]. However these models are restricted to a specific storage media and vessel geometries, which include placement and function of heat transfer elements. While useful for evaluation of particular storage system designs, the analyses in the literature are not suitable for general systematic assessment of storage vessel/media configurations against a set of performance targets. 
Adaptation of the models in the literature review to arbitrary media and vessel geometry would be too time consuming for them to be of practical value as a screening tool. To focus the development of detailed models on media and storage vessel configurations that have the potential to satisfy performance criteria, a tool was developed to screen candidate media and storage vessel designs. The screening tool identifies the range of parameters for the coupled media and storage vessel system that allow it to meet performance targets. The range of acceptable parameters forms a multi-dimensional volume, or envelope. Hence, the screening tool is referred to as the Acceptability Envelope Analysis.

In this document, the acceptability envelope is applied to metal hydride based storage systems in two ways. In the first case, the DOE technical targets for Year 2010, Year 2015 and the Ultimate targets [20] are considered to determine the range of geometrical and chemical-physical parameters, which are not known a priori, required for the coupled media and storage vessel. In the second application, the chemical and physical characteristics of the most promising of the existing metal hydrides are input (data of the problem) to acceptability envelope and some of the property values varied to see how the performance of these materials might be enhanced to approach the current DOE technical targets. In all cases the model is applied for different geometries and operating conditions. Results from the model provide a rough but nevertheless realistic idea about their potential to achieve a technical target equal to $40 \%$ of the DOE target.

\section{The acceptability envelope physical model for metal hydrides}

During charging, metal hydrides undergo exothermic chemical reactions that release a significant amount of heat. Conversely, during discharge the reactions are 
endothermic. At a given pressure, the temperature of the hydride determines whether it uptakes or releases hydrogen. Hence, heat transfer is the most important consideration in the design of storage vessels for use with metal hydrides. Typically, heat transfer within the storage vessel is accomplished either by packing the hydride between fins or around tubes that contain a flowing heat transfer fluid. In both cases, heat transfer within the hydride bed can be represented as a collection of periodic cells, in rectangular coordinate (RC) or cylindrical coordinate (CC) geometry. The packed hydride is referred to as a hydride bed, and it is through this packed bed that heat conduction to the heat transfer surfaces must take place.

With increased compaction of the metal hydride, mass transfer limitations may also play a role in the performance of the storage system. However, heat transfer, for this paper, was assumed to be the sole dominant factor in meeting performance targets.

The thermal model, which is the basis of the acceptability envelope, employs the following assumptions:

1. The process is steady-state, considering the hydrogen charging (discharging) process during a specified time ${ }^{2}$.

2. The heat transfer process is one dimensional ${ }^{3}$.

3. The thermal conductivity is isotropic and constant within the bed.

4. Convective heat transfer due to hydrogen passing through the bed is negligible ${ }^{4}$.

\footnotetext{
approach

${ }^{2}$ Thermal inertia of the material has been assumed negligible, starting from a conservative view.

${ }^{3}$ The thermal flux in the other directions has been assumed negligible from a conservative point of
} 
5. Mechanical work (i.e. compression or expansion) done to uptake (discharge) hydrogen (related to the pressure variation) is negligible.

\subsection{Rectangular coordinates geometry}

In a storage vessel where the metal hydride is layered between fins to enhance heat transfer a single cell can be represented in rectangular coordinates (RC) as shown in Figure 1.

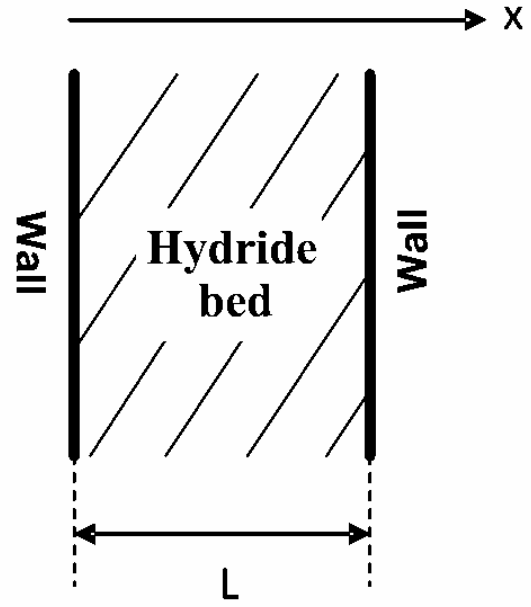

Figure 1. Model in rectangular coordinates (RC) for hydride layered between fins.

From assumptions 1-5 above, the hydride temperature is a function of $\mathrm{x}$, i.e. $\mathrm{T}=\mathrm{T}(\mathrm{x})$, and the energy balance in the hydride is given by Equation 1. In this equation the term $\mathrm{q}^{\prime \prime \prime}$ is the heat of reaction resulting from the charging (discharging) of hydrogen, which is balanced by thermal conduction inside the bed.

$$
\mathrm{k} \frac{\mathrm{d}^{2} \mathrm{~T}}{\mathrm{dx}^{2}}+\mathrm{q}^{\prime \prime \prime}=0
$$

${ }^{4}$ By this conservative approach the 'worst' case is considered, assuming negligible the convective flow heat transfer. 
where: $\quad k=$ Thermal conductivity $\left[\mathrm{W} / \mathrm{m}-{ }^{\circ} \mathrm{C}\right]$

$$
\begin{aligned}
& \mathrm{q}^{\prime \prime \prime}=\text { Volumetric heat source resulting from the heat of reaction during } \\
& \text { hydrogen uptake or discharge }\left[\mathrm{W} / \mathrm{m}^{3}\right] \\
& \mathrm{T}=\text { Temperature }\left[{ }^{\circ} \mathrm{C}\right]
\end{aligned}
$$

The volumetric heat source in Equation 1 is given by:

$$
\mathrm{q}^{\prime \prime \prime}=-\sum_{\mathrm{i}} \Delta \mathrm{H}_{\mathrm{i}} \frac{\Delta \mathrm{C}_{\mathrm{i}}}{\Delta \mathrm{t}}
$$

where: $\quad \Delta \mathrm{t}=$ Interval of time $[\mathrm{s}]$

$$
\begin{aligned}
\Delta \mathrm{H}_{\mathrm{i}}= & \text { Enthalpy of reaction for reaction } \mathrm{i}\left[\mathrm{J} /\left(\mathrm{g}-\mathrm{mol} \text { of } \mathrm{H}_{2}\right. \text { consumed in }\right. \\
& \text { reaction } \mathrm{i})] \\
\Delta \mathrm{C}_{\mathrm{i}}= & \text { Moles of } \mathrm{H}_{2} \text { consumed by reaction } \mathrm{i} \text { over the time interval } \Delta \mathrm{t}[\mathrm{mol} \\
& \left.\mathrm{H}_{2} / \mathrm{m}^{3}\right]
\end{aligned}
$$

In general the term $\Delta \mathrm{C}_{\mathrm{i}} / \Delta \mathrm{t}$ is obtained by integrating (over $\Delta \mathrm{t}$ ) the instantaneous rate of change, $\mathrm{dC}_{\mathrm{i}} / \mathrm{dt}$, which is determined by the reaction kinetics and depends on temperature, pressure and species concentrations. 
For complex hydrides (such as $\mathrm{NaAlH}_{4}$ ), characterized by a two (or more) step charging (discharging) reaction, the term $\mathrm{q}^{\prime \prime}$ can be expressed by the simplified Equation $2 \mathrm{~b}$ rather than $2 \mathrm{a}$.

$$
\mathrm{q}^{\prime \prime \prime}=-\Delta \mathrm{H}_{\text {overall }} \frac{\Delta \mathrm{C}_{\mathrm{f}}}{\Delta \mathrm{t}}=-\Delta \mathrm{H}_{\text {overall }} \frac{\rho_{\text {Hydride }}}{\mathrm{M}_{\text {Hyd_eff }} \mathrm{M}_{\mathrm{H} 2}} \frac{\Delta \mathrm{m}_{\mathrm{H} 2}}{\Delta \mathrm{t}}
$$

where: $\Delta \mathrm{H}_{\text {overall }}=$ The overall enthalpy of reaction $\left[\mathrm{J} /\left(\mathrm{g}-\mathrm{mol}\right.\right.$ of $\mathrm{H}_{2}$ for complete reaction)], which accounts for all intermediate chemical reactions between the initial and final form

$\Delta \mathrm{C}_{\mathrm{f}}=$ The total change in concentration in stored $\mathrm{H}_{2}$ over $\Delta \mathrm{t}\left[\mathrm{mol} \mathrm{H}_{2} / \mathrm{m}^{3}\right]$ $\rho_{\text {Hydride }}=$ Bulk density of the metal hydride in reference form $\left[\mathrm{kg} / \mathrm{m}^{3}\right]$ $\mathrm{M}_{\text {Hyd_eff }}=$ Mass of hydride (in reference form) required to load target amount of hydrogen in specified time (relates to kinetics) $[\mathrm{kg}]$ $\mathrm{M}_{\mathrm{H} 2}=$ Molecular weight of $\mathrm{H}_{2}[.002016 \mathrm{~kg} / \mathrm{g}-\mathrm{mol}]$ $\Delta \mathrm{m}_{\mathrm{H} 2}=$ Mass of hydrogen stored in metal hydride in time interval $\Delta \mathrm{t}[\mathrm{kg}]$

The value of $\Delta \mathrm{H}_{\text {overall }}$ has been assumed constant with varying operating temperatures and pressures. 
Two sets of boundary conditions have been considered for the integration of Equation 1. The first one uses constant wall temperatures, equal to $T_{s}$, at $x=0$ and $x=L$, see Equation 3.

$$
\begin{aligned}
& T(x=0)=T s \\
& T(x=L)=T s
\end{aligned}
$$

Integrate Equation 1 for the boundary conditions given by Equation 3 .

$$
\mathrm{T}(\mathrm{x})=-\mathrm{q}^{\prime \prime \prime} \frac{\mathrm{x}(\mathrm{x}-\mathrm{L})}{2 \mathrm{k}}+\mathrm{T}_{\mathrm{s}}
$$

where: $\quad L=$ Characteristic length associated with spacing of heat transfer surfaces

$$
\text { [m] }
$$

The derivative $\mathrm{dT} / \mathrm{dx}$ is:

$$
\frac{d T}{d x}=-q^{\prime \prime \prime}\left(\frac{2 x-L}{2 k}\right)+T_{s}
$$

Thus, the maximum of $\mathrm{T}(\mathrm{x})$, equal to $\mathrm{T}_{\max }$, occurs for $\mathrm{x}=\mathrm{L} / 2$. As a consequence, one has:

$$
\mathrm{T}_{\text {max }}=\mathrm{q}^{\prime \prime \prime} \frac{\mathrm{L}^{2}}{8 \mathrm{k}}+\mathrm{T}_{\mathrm{s}}
$$


Substitute Equation $2 \mathrm{~b}$ into Equation 6 and write the maximum temperature difference as $\Delta \mathrm{T}=\mathrm{T}_{\max }-\mathrm{T}_{\mathrm{s}}$. Then the maximum temperature difference inside the bed is expressed as ${ }^{5}$ :

$$
\Delta \mathrm{T}=-\Delta \mathrm{H}_{\text {overall }} \frac{\Delta \mathrm{C}_{\mathrm{f}}}{\Delta \mathrm{t}}\left(\frac{\mathrm{L}^{2}}{8 \mathrm{k}}\right)=-\Delta \mathrm{H}_{\text {overall }} \frac{\rho_{\text {Hydride }}}{\mathrm{M}_{\mathrm{Hyd}_{\text {_eff }} \mathrm{M}_{\mathrm{H} 2}}} \frac{\Delta \mathrm{m}_{\mathrm{H} 2}}{\Delta \mathrm{t}}\left(\frac{\mathrm{L}^{2}}{8 \mathrm{k}}\right)
$$

The hydride bed temperature profile given by Equation 4 for steady-state charging, with boundary conditions specified by Equation 3, is qualitatively shown in Figure 2a.

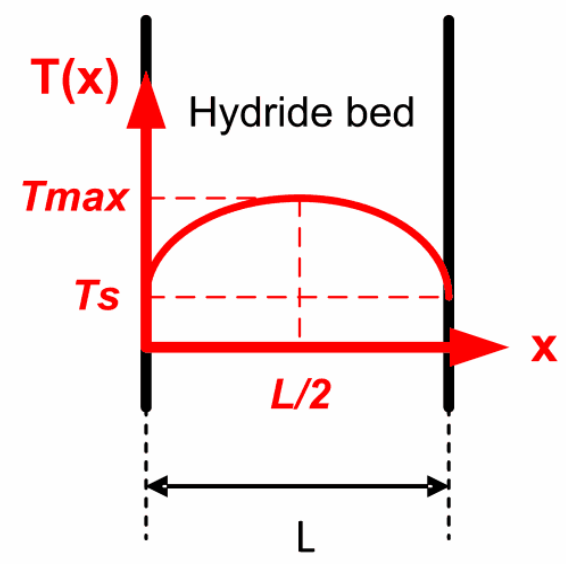

(a)

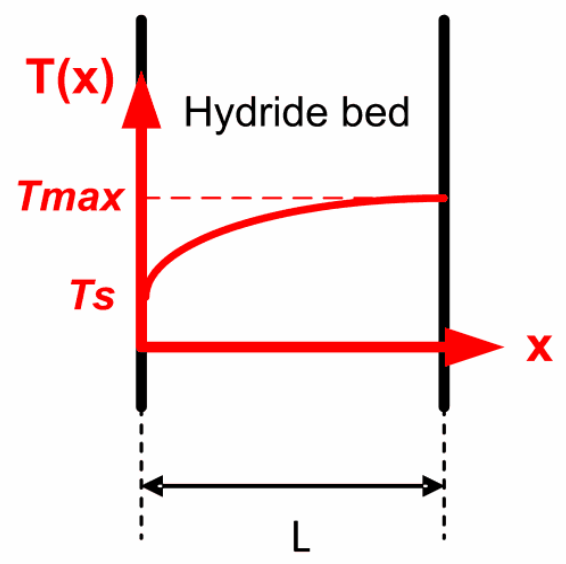

(b)

Figure 2. Hydride bed temperature profile during charging for: $(\mathrm{a}): \mathrm{T}(\mathrm{x}=0)=$ $\mathrm{T}(\mathrm{x}=\mathrm{L})=\mathrm{T}_{\mathrm{s}} ;(\mathrm{b}): \mathrm{T}(\mathrm{x}=0)=\mathrm{T}_{\mathrm{s}}$ and $\frac{\mathrm{dT}}{\mathrm{dx}}(\mathrm{x}=\mathrm{L})=0$.

\footnotetext{
${ }^{5}$ From here to the follow $\mathrm{H}_{2}$ charging is considered, unless otherwise indicated.
} 
The second set of boundary conditions considered is: no heat flux at the wall at $\mathrm{x}=\mathrm{L}$ and constant temperature, $\mathrm{T}_{\mathrm{s}}$, at the other wall, $\mathrm{x}=0$. Mathematically this is expressed as:

$\mathrm{T}(\mathrm{x}=0)=\mathrm{Ts}$

$\mathrm{dT} / \mathrm{dx}(\mathrm{x}=\mathrm{L})=0$

Integrate Equation 1 for the boundary conditions given in Equation 8

$$
T(x)=-q^{\prime \prime \prime} \frac{x(x-2 L)}{2 k}+T_{s}
$$

The derivative $\mathrm{dT} / \mathrm{dx}$ is:

$$
\frac{\mathrm{dT}}{\mathrm{dx}}=-\mathrm{q}^{\prime \prime \prime}\left(\frac{\mathrm{x}-\mathrm{L}}{\mathrm{k}}\right)
$$

The maximum of $\mathrm{T}(\mathrm{x})$, equal to $\mathrm{T}_{\max }$, occurs at the zero heat flux boundary, $\mathrm{x}=\mathrm{L}$. Hence, for the second set of boundary conditions:

$$
\mathrm{T}_{\max }=\mathrm{q}^{\prime \prime \prime} \frac{\mathrm{L}^{2}}{2 \mathrm{k}}+\mathrm{T}_{\mathrm{s}}
$$


Substitute Equation $2 \mathrm{~b}$ into Equation 11, then the maximum temperature difference in the hydride, $\Delta \mathrm{T}=\mathrm{T}_{\max }-\mathrm{T}_{\mathrm{s}}$, is:

$$
\Delta \mathrm{T}=-\Delta \mathrm{H}_{\text {overall }} \frac{\Delta \mathrm{C}_{\mathrm{f}}}{\Delta \mathrm{t}}\left(\frac{\mathrm{L}^{2}}{2 \mathrm{k}}\right)=-\Delta \mathrm{H}_{\text {overall }} \frac{\rho_{\text {Hydride }}}{\mathrm{M}_{\mathrm{Hyd}_{-} \text {eff }} \mathrm{M}_{\mathrm{H} 2}} \frac{\Delta \mathrm{m}_{\mathrm{H} 2}}{\Delta \mathrm{t}}\left(\frac{\mathrm{L}^{2}}{2 \mathrm{k}}\right)
$$

The hydride bed temperature profile given by Equation 9 for steady-state charging, with boundary conditions specified by Equation 8, is qualitatively shown in Figure 2b.

\subsection{Cylindrical coordinates geometry}

A storage vessel which effects heat transfer via hydride packed around tubes can be approximated as a collection of periodic cells. A heat transfer fluid with a controlled inlet temperature passes through the tubes at given flowrate and exchanges heat with the hydride. The representation of an individual cell is shown in Figure 3, in which the hydride bed is located in the annular region between $r_{1}$ and $r_{2}$ and the temperature profile is a function of $r$, i. e. $T=T(r)$, under cylindrical coordinates $(C C)$. 


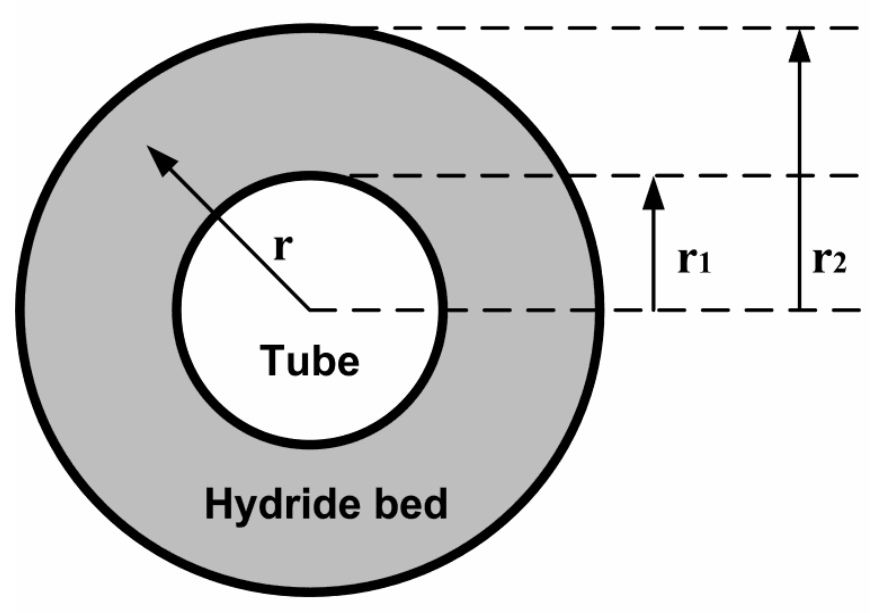

Figure 3. Model in cylindrical coordinates (CC) for hydride packed around a tube (from $r_{1}$ to $r_{2}$ )

For assumptions 1-5 in Section 3 the bed energy balance, in $\mathrm{CC}$, is given by Equation 13.

$$
\mathrm{k} \frac{1}{\mathrm{r}} \frac{\mathrm{d}}{\mathrm{dr}}\left(\mathrm{r} \frac{\mathrm{dT}}{\mathrm{dr}}\right)+\mathrm{q}^{\prime \prime \prime}=0
$$

The volumetric heat source, $\mathrm{q}^{\prime \prime \prime}$, in Equation 13 is given by Equation 2b, as it was for the RC form of the geometry.

As for the RC geometry, two sets of boundary conditions have been considered. The first condition sees constant wall temperature, $\mathrm{T}_{\mathrm{s}}$, applied at $\mathrm{r}=\mathrm{r}_{1}$ and $\mathrm{r}=\mathrm{r}_{2}$, as given in Equation 14.

$$
\mathrm{T}\left(\mathrm{r}=\mathrm{r}_{1}\right)=\mathrm{T}_{\mathrm{s}}
$$


$\mathrm{T}\left(\mathrm{r}=\mathrm{r}_{2}\right)=\mathrm{T}_{\mathrm{s}}$

Consequently, integrating Equation 13 gives the temperature T(r) as:

$$
\mathrm{T}(\mathrm{r})=-\frac{\mathrm{q}^{\prime \prime \prime}}{4 \mathrm{k}} \mathrm{r}^{2}+\mathrm{C}_{1} \ln (\mathrm{r})+\mathrm{C}_{2}
$$

$\mathrm{C}_{1}$ and $\mathrm{C}_{2}$ are integration constants that are determined from the boundary conditions of Equation 14. Thus:

$$
\mathrm{C}_{1}=2 \gamma \frac{\mathrm{q}^{\prime \prime \prime}}{4 \mathrm{k}} \mathrm{r}_{1}^{2}
$$

and

$$
\mathrm{C}_{2}=\mathrm{T}_{\mathrm{s}}+\frac{\mathrm{q}^{\prime \prime \prime}}{4 \mathrm{k}} \mathrm{r}_{1}^{2}\left[1-2 \gamma \ln \left(\mathrm{r}_{1}\right)\right]
$$

where:

$$
\gamma=\frac{\left(\frac{\mathrm{r}_{2}}{\mathrm{r}_{1}}\right)^{2}-1}{2 \ln \left(\frac{\mathrm{r}_{2}}{\mathrm{r}_{1}}\right)}
$$

Thus, from Equations 15-18, the hydride temperature profile, $\mathrm{T}(\mathrm{r})$, can be expressed as follows: 


$$
\mathrm{T}(\mathrm{r})=\frac{\mathrm{q}^{\prime \prime \prime}}{4 \mathrm{k}}\left[\mathrm{r}_{1}^{2}\left(1+2 \gamma \ln \left(\frac{\mathrm{r}}{\mathrm{r}_{1}}\right)\right)-\mathrm{r}^{2}\right]+\mathrm{T}_{\mathrm{s}}
$$

The derivative, $\mathrm{dT} / \mathrm{dr}$, of Equation 19 is:

$$
\frac{\mathrm{dT}}{\mathrm{dr}}=\frac{\mathrm{q}^{\prime \prime \prime}}{4 \mathrm{k}}\left[2 \gamma \frac{\mathrm{r}_{1}^{2}}{\mathrm{r}}-2 \mathrm{r}\right]
$$

Setting $\mathrm{dT} / \mathrm{dr}$ equal to zero gives the radial location, $r_{\max }$, of the maximum temperature, $T_{\max }$.

$$
\mathrm{r}=\mathrm{r}_{\max }=\mathrm{r}_{1} \sqrt{\gamma}
$$

As a consequence, $\mathrm{T}_{\max }$ is given by:

$$
\mathrm{T}_{\max }=\frac{\mathrm{q}^{\prime \prime \prime}}{4 \mathrm{k}} \mathrm{r}_{1}^{2}[1-\gamma+2 \gamma \ln (\sqrt{\gamma})]+\mathrm{T}_{\mathrm{s}}
$$

Substituting Equation $2 \mathrm{~b}$ into Equation 22 gives the maximum temperature difference, $\Delta \mathrm{T}=\mathrm{T}_{\max }-\mathrm{T}_{\mathrm{s}}$, within the hydride as: 


$$
\begin{aligned}
\Delta T & =-\Delta H_{\text {overall }}\left(\frac{\Delta C_{f}}{\Delta t}\right)\left(\frac{r_{1}^{2}}{4 k}\right)[1-\gamma+2 \gamma \ln (\sqrt{\gamma})] \\
& =-\Delta H_{\text {overall }}\left(\frac{\rho_{\text {Hydride }}}{M_{H_{y d \_} \text {eff }} M_{H 2}}\right)\left(\frac{\Delta m_{H 2}}{\Delta t}\right)\left(\frac{r_{1}^{2}}{4 k}\right)[1-\gamma+2 \gamma \ln (\sqrt{\gamma})]
\end{aligned}
$$

The second set of boundary conditions for the CC geometry corresponds to a symmetry boundary condition at the outer wall. This set of boundary conditions assumes a fixed temperature, $\mathrm{T}_{\mathrm{s}}$, at the inner wall and zero heat flux at the outer wall, as given in Equations 24.

$$
\begin{aligned}
& \mathrm{T}\left(\mathrm{r}=\mathrm{r}_{1}\right)=\mathrm{T}_{\mathrm{s}} \\
& \mathrm{dT} / \mathrm{dr}\left(\mathrm{r}=\mathrm{r}_{2}\right)=0
\end{aligned}
$$

Integrating Equation 13 with the boundary conditions of Equations 24 gives:

$$
T(r)=T_{s}+\frac{q^{\prime \prime \prime}}{4 k}\left[2 r_{2}^{2} \ln \left(\frac{r}{r_{1}}\right)-\left(r^{2}-r_{1}^{2}\right)\right]
$$

The derivative $\mathrm{dT} / \mathrm{dr}$ is:

$$
\frac{d T}{d r}=\frac{q^{\prime \prime \prime}}{2 k}\left(\frac{r_{2}^{2}}{r}-r\right)
$$


Setting $d T / d r=0$ gives the location, $\mathrm{r}_{\max }$, of the maximum temperature, $\mathrm{T}_{\max }$, which is $r_{\max }=r_{2}$. This is physically deducible considering the condition of no heat flux at $r=r_{2}$. Thus, $T_{\max }$ is:

$$
T_{\max }=T_{s}+\frac{q^{\prime \prime \prime}}{4 k}\left(r_{2}^{2}-r_{1}^{2}\right)\left(\frac{\left(\frac{r_{2}}{r_{1}}\right)^{2}}{\gamma}-1\right)
$$

Substituting Equation $2 \mathrm{~b}$ into Equation 27 gives the maximum temperature difference inside the bed, $\Delta \mathrm{T}$, as:

$$
\begin{aligned}
& \Delta T=-\Delta H_{\text {overall }}\left(\frac{\Delta C_{f}}{\Delta t}\right) \frac{\left(r_{2}^{2}-r_{1}^{2}\right)\left(\frac{\left(\frac{r_{2}}{r_{1}}\right)^{2}}{\gamma}-1\right)}{4 k} \\
& \left.=-\Delta H_{\text {overall }}\left(\frac{\rho_{\text {Hydride }}}{M_{\text {Hyd_eff }} M_{H 2}}\right)\left(\frac{\Delta m_{H 2}}{\Delta t}\right) \frac{\left(r_{2}^{2}-r_{1}^{2}\right)\left(\frac{\left(\frac{r_{2}}{r_{1}}\right)^{2}}{\gamma}-1\right)}{4 k}\right)
\end{aligned}
$$

\subsection{Application of the acceptability envelope}

Generally speaking, Equations 7, 12, 23 and 28 have the same form and can be written as a single equation: 


$$
\begin{aligned}
\Delta T & =-\frac{1}{m}\left[\frac{\mathrm{L}^{2}}{k} \Delta H_{\text {overall }}\left(\frac{\Delta C_{f}}{\Delta t}\right)\right] \\
& =-\frac{1}{m}\left[\frac{\mathrm{L}^{2}}{k} \Delta H_{\text {overall }}\left(\frac{\rho_{\text {Hydride }}}{M_{\text {Hyd_eff }} M_{H 2}}\right)\left(\frac{\Delta m_{H 2}}{\Delta t}\right)\right]
\end{aligned}
$$

where: $\quad \mathrm{m}=8$ for $\mathrm{RC}$.

$$
=4 \text { for } \mathrm{CC} \text {. }
$$

$\mathrm{L}=$ Characteristic distance between heat transfer surfaces for RC geometry with fixed temperatures at the inner and outer surfaces (L).

$=$ Twice the distance between heat transfer surfaces for RC geometry with the temperature fixed at the inner surface and adiabatic condition at outer surface $(2 \mathrm{~L})$.

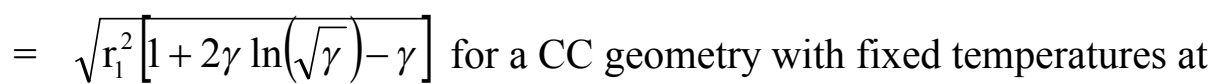
the inner and outer surfaces.

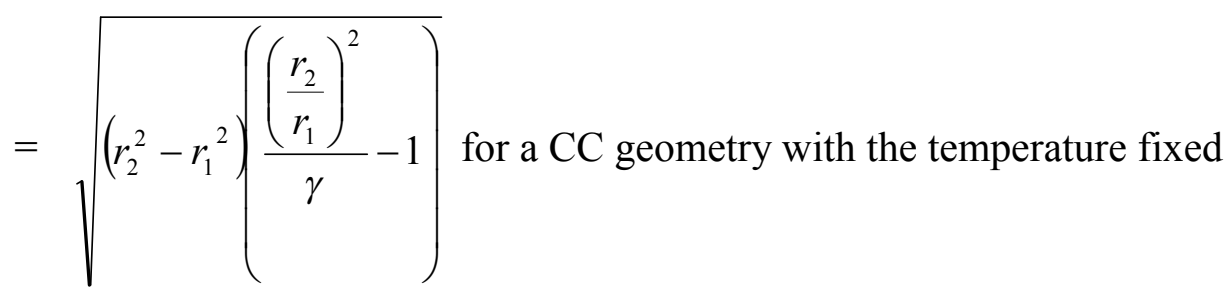
at the inner surface and an adiabatic outer surface.

It must be emphasized that while $\mathrm{L}$ (Equation 29) is directly related to the characteristic distance between heat transfer surfaces for a RC geometry, see Figure 1, it 
is a function of $r_{1}$ and $r_{2}$ for the CC geometry, see Figure 3. Even so, for all cases $\mathrm{L}$ serves as a metric for the spacing of heat transfer surfaces.

Of the parameters in Equation 29 the temperature range, $\Delta \mathrm{T}$, requires a more detailed explanation. $\Delta \mathrm{T}$ ties the kinetics of the media to the performance of the storage vessel and, hence, to the technical targets. An example of establishing $\Delta \mathrm{T}$ may be had by considering the reaction rates for $\mathrm{NaAlH}_{4}+2 \% \mathrm{TiCl}_{3} \times 1 / 3 \mathrm{AlCl}_{3}+0.5 \% \mathrm{FeCl}_{3}$ [21], which are shown as a function of temperature and pressure in Figure 4. This figure shows the time required to charge $5.5 \mathrm{~kg}$ of hydrogen to the metal hydride, originally in the form of $\mathrm{NaH}$, which is maintained at the temperature indicated along the abscissa and the pressure indicated along the ordinate axis. The combined temperatures and pressures that allow $5.5 \mathrm{~kg}$ of hydrogen to be stored in $4.2 \mathrm{~min}$ are indicated by the solid curve in the figure. The 4.2 min time used in the example is the charging time from the DOE 2010 technical targets and the $5.5 \mathrm{~kg}$ mass of stored hydrogen accounts for $5 \mathrm{~kg}$ required as fuel to power the vehicle plus $10 \%$ more to be burned to heat the hydride bed so that hydrogen is discharged at an adequate rate. More details on this study can be found in $[22]$.

Assuming the pressure is maintained at 150 bar, the charging rate of 4.2 min can be had for a range of temperatures between 133 and $163{ }^{\circ} \mathrm{C}$. This implies that a temperature interval, $\Delta \mathrm{T}=30^{\circ} \mathrm{C}$, would permit charging the vessel in $4.2 \mathrm{~min}$ or less, based on the hydride kinetics. Due to the lack of data for some media, analyzed in this work, this temperature range is based on engineering judgment as the baseline value in the acceptability envelope analysis. For the temperature interval, $\Delta \mathrm{T}$, the range of 
coupled hydride parameters and spacing of heat transfer surfaces are determined so that the storage system to meets the technical targets.

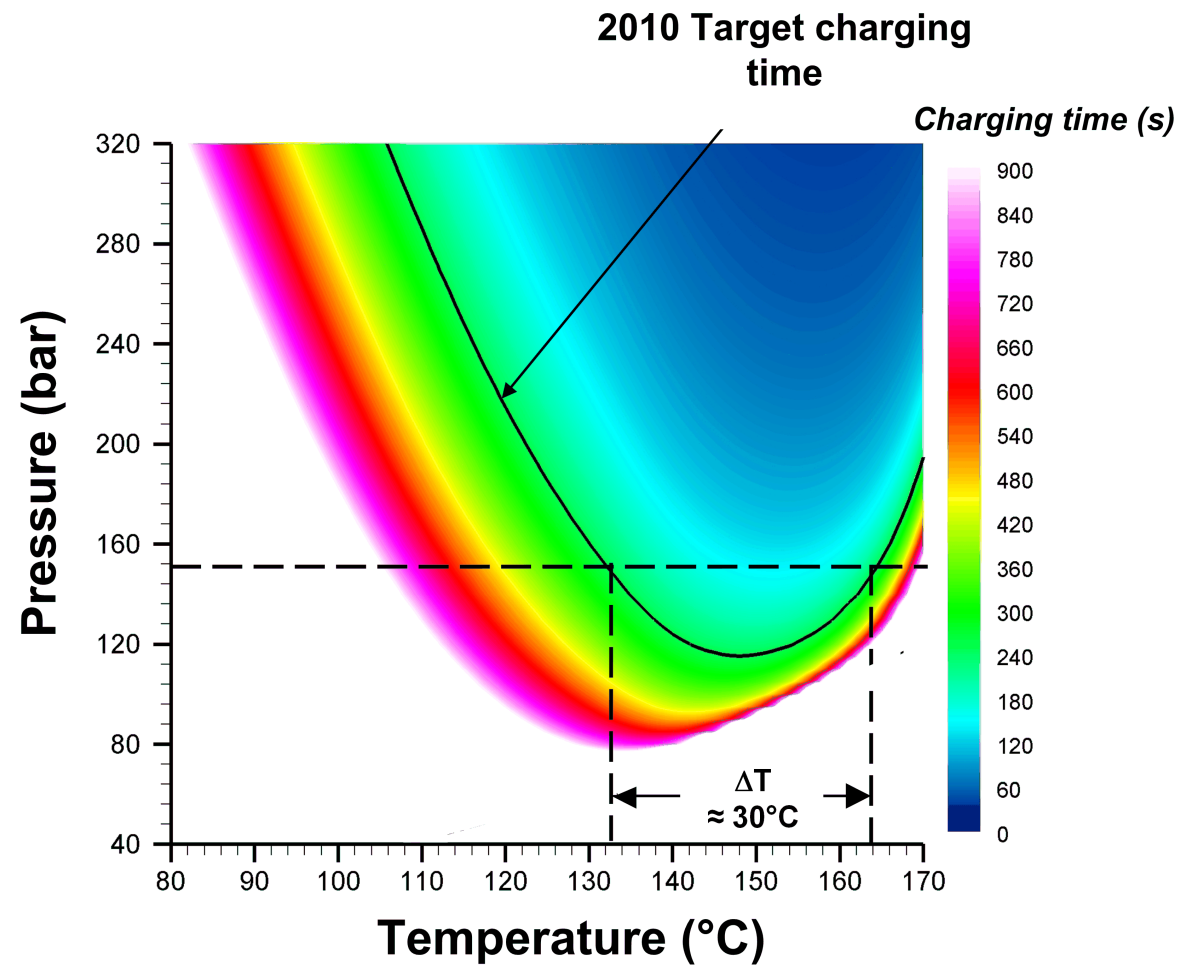

Figure 4. Use of hydride kinetics (filling time) to establish the parameter $\Delta \mathrm{T}$.

Equation 29 can be rearranged as:

$$
\left(\frac{1}{\mathrm{~L}^{2}}\right)\left(\frac{k M_{H_{y d} \text { eeff }} \Delta T}{-\Delta H_{\text {overall }} \rho_{\text {Hydride }}}\right)=\frac{1}{m M_{H 2}}\left(\frac{\Delta m_{H 2}}{\Delta t}\right)
$$

Table 1 gives the physical interpretation of the parameters in Equation 30.

Equation 30 shows the relationship among the system parameters, namely: the characteristic spacing of heat transfer surfaces (L), the physical and chemical media parameters (on the left side of Equation 30) and the charging rate (on the right side of Equation 30). 


\section{Table 1 Physical Interpretation of Parameters for Acceptability Envelope}

L

$\Delta \mathrm{T}$

Myd_eff

$\Delta \mathrm{H}_{\text {overall }}$

$\rho_{\text {Hydride }}$

$\mathrm{k}$

$\Delta \mathrm{m}_{\mathrm{H} 2} / \Delta \mathrm{t}$
Measure of characteristic distance between heat transfer surfaces [m]

Temperature range for acceptable chemical kinetics (to give charge/discharge rate of $\left.\Delta \mathrm{m}_{\mathrm{H} 2} / \Delta \mathrm{t}\right)\left[{ }^{\circ} \mathrm{C}\right]$

Mass of hydride (in reference form) required to load target amount of hydrogen in a specified amount of time (relates to kinetics) $[\mathrm{kg}]$

Overall heat of reaction $\left[\mathrm{J} /\left(\mathrm{g}-\mathrm{mol}\right.\right.$ of $\mathrm{H}_{2}$ for complete reaction $\left.)\right]$

Hydride density (in reference form) $\left[\mathrm{kg} / \mathrm{m}^{3}\right]$

Bed thermal conductivity $\left[\mathrm{W} / \mathrm{m}-{ }^{\circ} \mathrm{C}\right]$

Required rate of charging/discharging $\left[\mathrm{kg}-\mathrm{H}_{2} / \mathrm{s}\right]$

In Figure 5 the parameter grouping,

$$
\left(\frac{1}{\mathrm{~L}^{2}}\right)\left(\frac{k M_{H_{\text {Hd_eff }}} \Delta T}{-\Delta H_{\text {overall }} \rho_{\text {Hydride }}}\right)
$$

from the left hand side of Equation 30, which is equal to $\left(1 / \mathrm{mM}_{\mathrm{H} 2}\right)\left(\Delta \mathrm{m}_{\mathrm{H} 2} / \Delta \mathrm{t}\right)$, is plotted vs. $\Delta \mathrm{m}_{\mathrm{H} 2} / \Delta \mathrm{t}$. In this graphical approach the relation between the parameters in Equation 30 is reduced to a one input-one output linear problem, with the ordinate variable giving information about the "link" between the coupled geometric, physical and chemical characteristics of the bed. The column labeled $\left(1 / \mathrm{mM}_{\mathrm{H} 2}\right)\left(\Delta \mathrm{m}_{\mathrm{H} 2} / \Delta \mathrm{t}\right)$ in Table 2 gives the values of the parameter grouping in Expression 31 corresponding to the three DOE charging rate targets highlighted in Figure 5. 
Table 2 Hydrogen Charging Rates From the DOE Technical Targets

\begin{tabular}{|l|l|l|l|l|}
\hline Target & SGC* & $\begin{array}{l}\Delta \mathbf{t}(\mathbf{m i n}) \\
\text { for 5 } \mathbf{~ k g ~ H}\end{array}$ & $\begin{array}{l}\Delta \mathbf{m}_{\mathbf{H} 2} / \Delta \mathbf{t} \\
(\mathbf{k g} / \mathbf{s})\end{array}$ & $\left(1 / \mathrm{mM}_{\mathrm{H} 2}\right)\left(\Delta \mathrm{m}_{\mathrm{H} 2} / \Delta \mathrm{t}\right)$ \\
\hline DOE 2010 & 0.045 & 4.2 & 0.0198 & $2.46(\mathrm{CC})$ \\
& & & & $1.23(\mathrm{RC})$ \\
\hline DOE 2015 & 0.055 & 3.3 & 0.0253 & $\begin{array}{l}3.13(\mathrm{CC}) \\
1.57(\mathrm{RC})\end{array}$ \\
\hline $\begin{array}{l}\text { DOE } \\
\text { Ultimate }\end{array}$ & 0.075 & 2.5 & 0.0333 & $\begin{array}{l}4.13(\mathrm{CC}) \\
2.07(\mathrm{RC})\end{array}$ \\
\hline
\end{tabular}

*System Gravimetric Capacity $\left(\mathrm{kg}_{\mathrm{H} 2} / \mathrm{kg}_{\text {Overall System }}\right)$

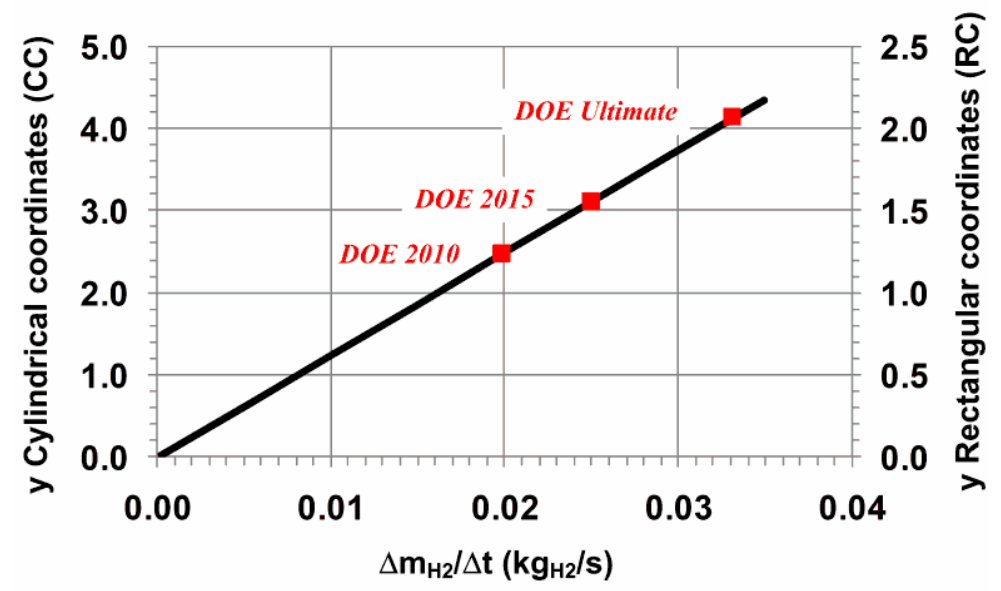

Figure 5. Acceptability envelope for rectangular (RC) and cylindrical coordinates (CC). The three DOE scenarios are shown in the figure. The parameter y is equal to $\left(\frac{1}{\mathrm{~L}^{2}}\right)\left(\frac{k M_{H_{y d} \text { eff }} \Delta T}{-\Delta H_{\text {overall }} \rho_{\text {Hydride }}}\right)$

Once $\left(\frac{1}{\mathrm{~L}^{2}}\right)\left(\frac{k M_{\text {Hyd_eff }_{\text {ef }}} \Delta T}{-\Delta H_{\text {overall }} \rho_{\text {Hydride }}}\right)$ is determined from Figure 5, the value of $\mathrm{L}$ can be evaluated, being equal to 


$$
\mathrm{L}=\sqrt{\left(\frac{k M_{H_{y d} \text { eff }} \Delta T}{-\Delta H_{\text {overall }} \rho_{\text {Hydride }}}\right)\left(\frac{1}{y}\right)}
$$

where: $\quad \mathrm{y}=\left(1 / \mathrm{mM}_{\mathrm{H} 2}\right)\left(\Delta \mathrm{m}_{\mathrm{H} 2} / \Delta \mathrm{t}\right)$.

The sensitivity of $\mathrm{L}$ to the changes in the other quantities can be evaluated by Equation 32. L variation (in terms of ratio between final and initial value of the quantity) is proportional to the square root of the variation (ratio between final and initial value of

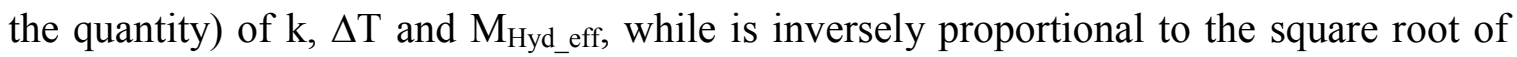
the variation (ratio between final and initial value) of $\rho_{\text {Hydride }}$ and $\Delta \mathrm{H}_{\text {overall. }}$ Thus, for instance, an increase of $\Delta \mathrm{T}$ value of $50 \%$ relative to its initial value results in an increased L value of approximately $22.5 \%$.

\section{Selected cases results and comments}

The linear relationship, given by Equation 30, makes the acceptability envelope tool very flexible and straightforward. Generally speaking, each parameter can be assumed as unknown quantity to be evaluated. For the present paper the analysis is applied in two ways.

First, the acceptability envelope is used to find the range of physical, chemical and geometrical characteristics of the coupled media and vessel system so that it satisfies 
the DOE technical targets, which provide the parameter $\left(\Delta \mathrm{m}_{\mathrm{H} 2} / \Delta \mathrm{t}\right)$. This application highlights the potential of the tool to solve a "direct" problem analysis, in which the features of the storage system are not known a priori and represent the output of the problem.

In the second application, the acceptability envelope is used to analyze and compare selected materials, given a determined target, and to show which media have the best technical potential. In this case the material properties are assumed as known $a$ priori and the acceptability envelope tool is used to solve an "inverse problem", assessing the geometrical quantity which defines the coupled storage system for a given target.

\subsection{DOE technical target analysis: dependence of $L$ on density, thermal conductivity and heat of reaction}

The first application, which is based on the DOE technical targets, uses the quantity $\Delta \mathrm{m}_{\mathrm{H} 2} / \Delta \mathrm{t}$ as the only datum (constraint) of the problem, with $\mathrm{L}$ being the unknown quantity (both for $\mathrm{CC}$ and $\mathrm{RC}$ ). The other parameters involved in the problem are: $m$ and $M_{H 2}$ which are constants and $\mathrm{k}, \Delta \mathrm{T}, \Delta \mathrm{H}_{\mathrm{overall}}, \rho_{\mathrm{Hydride}}$ and $\mathrm{M}_{\mathrm{Hyd} \_ \text {eff, }}$ which are degrees of freedom. Here, values of $\Delta \mathrm{T}$ and $\mathrm{M}_{\mathrm{Hyd} \_ \text {eff }}$ are assumed beforehand. The value of $\mathrm{M}_{\text {Hyd_eff }}$ can be determined by noting that:

$$
\mathrm{M}_{\mathrm{Hyd} \_ \text {eff }}=\frac{\left(\Delta \mathrm{m}_{\mathrm{H} 2} / \Delta \mathrm{t}\right)}{\mathrm{wf} / \Delta \mathrm{t}}
$$

where $\mathrm{wf}=$ hydride gravimetric capacity, expressed as $\left[\mathrm{kg}_{\mathrm{H} 2} / \mathrm{kg}_{\mathrm{Hydride}}\right]^{6}$.

\footnotetext{
${ }^{6}$ wf refers to the bed hydride material, hereafter, without considering the overall storage systems (i.e. BOP equipment, auxiliaries, etc)
} 
In general wf is a property of the media. For the present case, the material properties are not known a priori, but the overall system gravimetric capacity (SGC) value is known from the DOE target specifications. Thus the value of wf can be assessed indirectly assuming data relative to the ratio between hydride weight and overall system weight from literature, experiments, or other sources [21], with the assumed values reported in Table 3. Consequently $\mathrm{M}_{\mathrm{Hyd} \_ \text {eff }}\left(\right.$ Table 3) can be evaluated with $\Delta \mathrm{m}_{\mathrm{H} 2}$ and $\Delta \mathrm{t}$ values from Table 2 .

Table $3 \quad$ Values of $M_{H y d \_ \text {eff }}$ for the Technical Targets

\begin{tabular}{|l|l|l|l|l|}
\hline Target & SGC & $\begin{array}{l}\text { Hydride weight/System } \\
\text { weight }\end{array}$ & wf & $\begin{array}{l}\mathbf{M}_{\text {Hyd_eff }}[\mathbf{k g}] \text { for 5 kg of } \\
\mathbf{H}_{\mathbf{2}}\end{array}$ \\
\hline DOE 2010 & 0.045 & $0.5^{*}$ & 0.086 & $58.1(\Delta \mathrm{t}=4.2 \mathrm{~min})$ \\
\hline DOE 2015 & 0.055 & $0.55^{* *}$ & 0.100 & $50.0(\Delta \mathrm{t}=3.3 \mathrm{~min})$ \\
\hline $\begin{array}{l}\text { DOE } \\
\text { Ultimate }\end{array}$ & 0.075 & $0.60^{* *}$ & 0.125 & $40.0(\Delta \mathrm{t}=2.5 \mathrm{~min})$ \\
$* * *$ & $\begin{array}{l}\text { From [16] } \\
\text { Based on engineering judgment and anticipated improvements }\end{array}$ \\
\hline
\end{tabular}

The value of $\Delta \mathrm{T}$ has been assumed equal to $30^{\circ} \mathrm{C}$, based upon the discussion in Section 3.3.

Given the assumptions described above, selected parametric analyses for all the degrees of freedom of the problem were carried out with $\mathrm{M}_{\mathrm{Hyd} \_ \text {eff }}$ preliminary determined as described above for each of the technical targets. The thermal conductivity was allowed to range from $0.1 \mathrm{~W} / \mathrm{m}-{ }^{\circ} \mathrm{C}$ to $5 \mathrm{~W} / \mathrm{m}-{ }^{\circ} \mathrm{C}$, the bed density ranged from $720 \mathrm{~kg} / \mathrm{m}^{3}$ to $8000 \mathrm{~kg} / \mathrm{m}^{3}$, and the enthalpy of reaction ranged from $15 \mathrm{~kJ} / \mathrm{mol} \mathrm{H}_{2}$ to $70 \mathrm{~kJ} / \mathrm{mol} \mathrm{H}_{2}$.

Results obtained for the DOE 2010 year target, for both CC and RC coordinates, are shown in Figures 6 and 7. 
SRNL-TR-2011-00211

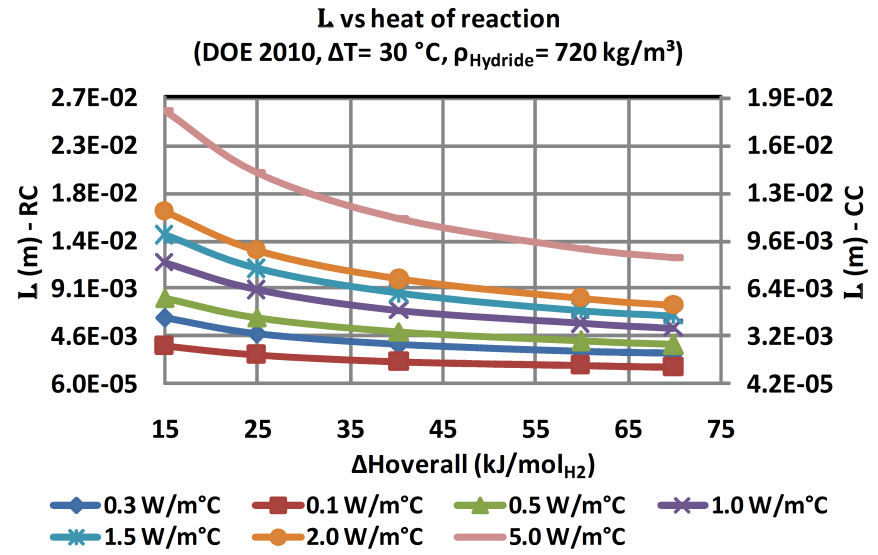

Figure 6. L profiles for the DOE 2010 technical targets in rectangular (RC) and cylindrical (CC) coordinates. The heat of reaction and hydride thermal conductivity were allowed to vary, while the bed density was fixed at $720 \mathrm{~kg} / \mathrm{m}^{3}$ and $\Delta \mathrm{T}=30^{\circ} \mathrm{C}$, with $\mathrm{M}_{\text {Hyd_eff }}$ value reported in Table 3.

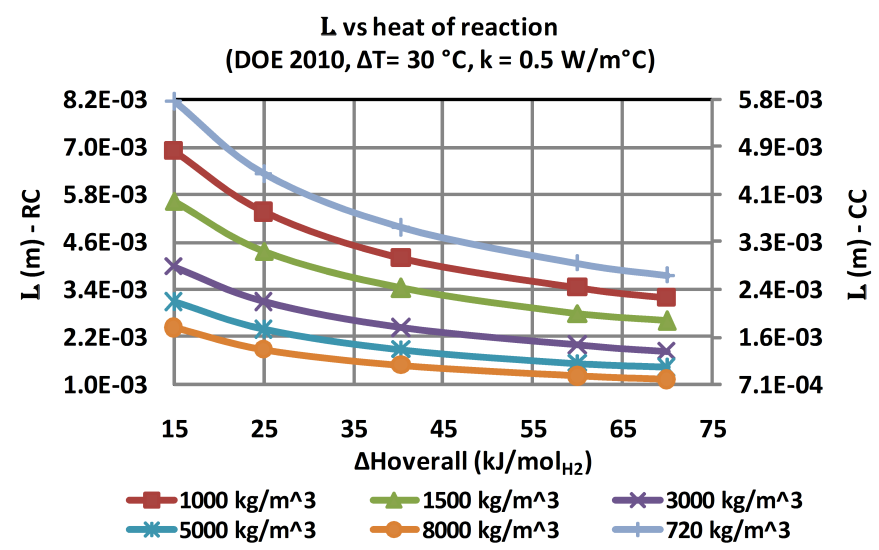

Figure 7. L profiles for the 2010 DOE technical targets in rectangular (RC) and cylindrical (CC) coordinates. The heat of reaction and hydride bulk density were allowed to vary, while the bed thermal conductivity was fixed at $0.5 \mathrm{~W} / \mathrm{m}-{ }^{\circ} \mathrm{C}$ and $\Delta \mathrm{T}=30^{\circ} \mathrm{C}$, with $\mathrm{M}_{\mathrm{Hyd} \_ \text {eff }}$ value reported in Table 3. 
Profiles for the DOE 2015 and DOE Ultimate targets, evaluated with the quantities reported in Table 2 and 3, are qualitatively the same of the DOE 2010 profiles shown in Figure 6 and 7.

However, moving from the DOE 2010 target, to the DOE 2015 target, requires in a reduction in charging time of more than $21 \%$ and an increase in the wf value of approximately $14 \%$. To accommodate this, the value of $\mathrm{L}$ must decrease $\sim 18 \%$. For the DOE Ultimate target, the charging time is reduced by more than $40 \%$ and the wf value is increased of approximately $31 \%$ relative to the DOE 2010 target, requiring a corresponding decrease of more than $36 \%$ in $\mathrm{L}$. As noted above, for RC geometries $\mathrm{L}$ is simply the characteristic distance between heat transfer surfaces (or twice the distance), however, for cylindrical geometries $\mathrm{L}$ is a function of $r_{1}$ and $r_{2}\left(\right.$ or $\left.r_{2} / r_{1}\right)$. Once $L$ is determined for a CC geometry, specifying either $r_{1}$ or $r_{2}$ allows calculation of the

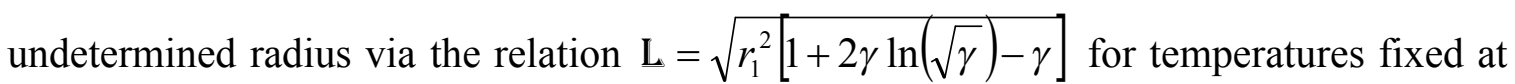
both surfaces, or the relation $\mathrm{L}=\sqrt{\left(r_{2}^{2}-r_{1}^{2}\right)\left(\frac{\left(\frac{r_{2}}{r_{1}}\right)^{2}}{\gamma}-1\right)}$ for the temperature fixed at the inner surface and an adiabatic outer surface.

\subsection{Comparison among selected materials}

The acceptability envelope tool was also used to analyze and compare the potential of different materials given a determined target. For the present analysis the target was assumed equal to $40 \%$ of the 2010 DOE technical specifications. Thus, the 
SGC value is approximately $1.8 \%, \Delta \mathrm{t}$ is equal to $630 \mathrm{~s}, \Delta \mathrm{m}_{\mathrm{H} 2} / \Delta \mathrm{t}$ is equal to $0.00794 \mathrm{~kg} / \mathrm{s}$ and $y$ value, with reference to Figure 5, is approximately 1 for $\mathrm{CC}$ and 0.5 for RC. This implies, being $y$ inversely proportional to $\mathrm{L}^{2}$, that $\mathrm{L}$ value for the $40 \%$ of the $2010 \mathrm{DOE}$ target is approximately 55\% higher than the 2010 DOE target value, fixing the other quantities.

Taking Equation 30 into account, for this analysis the data of the problem are: $\Delta \mathrm{m}_{\mathrm{H} 2} / \Delta \mathrm{t}$ and $\mathrm{k}, \Delta \mathrm{T}, \Delta \mathrm{H}_{\mathrm{overall}}$ (indicated as $\Delta \mathrm{H}$ hereafter), $\rho_{\text {Hydride }}$ (indicated as $\rho$ hereafter) and $\mathrm{M}_{\mathrm{Hyd} \_ \text {eff }}$ which relates (directly and indirectly) to physical and chemical characteristics of the material. The quantities $m$ and $M_{H_{2}}$ are constants. Consequently $\mathrm{L}$ is the only unknown quantity (both for $\mathrm{CC}$ and $\mathrm{RC}$ ).

Due to the lack of data for some materials, the value of $\Delta \mathrm{T}$ was assumed equal to $30^{\circ} \mathrm{C}$ as described at Section $3.3^{7}$, unless otherwise indicated. The value of $\mathrm{M}_{\text {Hyd_eff }}$ was assessed as indicated by Equation 33, with the specific material wf value.

Two different scenarios were selected for all the materials. The first, which is the baseline case $(\mathrm{BC})$ considers the unmodified, base powder medium as the constitutive material of the hydrogen storage system. The second case (GA) sees the addition of graphite $(10 \%$ of the material weight) to the storage material so as to increase the overall thermal conductivity.

Sensitivity analyses were conducted to evaluate the impact on system design of uncertainties in the parameters that characterize the material. Specifically, an analysis

\footnotetext{
${ }^{7}$ This is a conservative assumption, considering, for this case, the $40 \%$ of the 2010 DOE technical targets.
} 
was performed over a range of thermal conductivities and charging times, about the reference values, to evaluate the impact on the spacing of heat transfer surfaces. For BC media the thermal conductivity varied from 0.2 to $1.2 \mathrm{~W} / \mathrm{m}-{ }^{\circ} \mathrm{C}$, while for GA media it ranged from 5 to $10 \mathrm{~W} / \mathrm{m}-{ }^{\circ} \mathrm{C}$.

A charging rate that is $40 \%$ of the 2010 DOE target has been assumed. Given the 2010 target charging time of 4.3 minutes, meeting $40 \%$ of the charging rate implies a charging time of $630 \mathrm{~s}$. To bracket various charging rates, parametric analyses have been carried for charging times varying from 250 to 2000 s. In this way, parameters can be determined that allow the metal hydride and storage vessel to charge within $40 \%$ of the DOE target rate.

\subsection{1 $\mathrm{NaAlH}_{4}$ material}

The acceptability envelope model has been applied to $\mathrm{NaAlH}_{4}$ material-based bed with the hypotheses and features reported above. Reference values of density (720 $\left.\mathrm{kg} / \mathrm{m}^{3}\right)$, heat of reaction $\left(40 \mathrm{~kJ} / \mathrm{molH}_{2}\right)$, weight fraction wf $(3 \%)$ and thermal conductivity $\left(0.3 \mathrm{~W} / \mathrm{m}-{ }^{\circ} \mathrm{C}\right)$ have been assumed based on data available from [21,23] for the baseline case. Regarding the graphite added case, the data (density equal to $870 \mathrm{~kg} / \mathrm{m}^{3}$, heat of reaction assumed equal to the $\mathrm{BC}$ case, weight fraction equal to $2.7 \%$, thermal conductivity equal to $8.5 \mathrm{~W} / \mathrm{m}-{ }^{\circ} \mathrm{C}$ ) have been taken from [24] and on the basis of assumptions and evaluations [25].

Figures 8 shows the characteristic spacing of heat transfer surfaces for a $\mathrm{NaAlH}_{4}$ bed in rectangular coordinate geometry with the temperature fixed at both surfaces, for both the $\mathrm{NaAlH}_{4}$ - BC case (Figure 8 a) and the $\mathrm{NaAlH}_{4}$ - GA case (Figure $8 \mathrm{~b}$ ). 

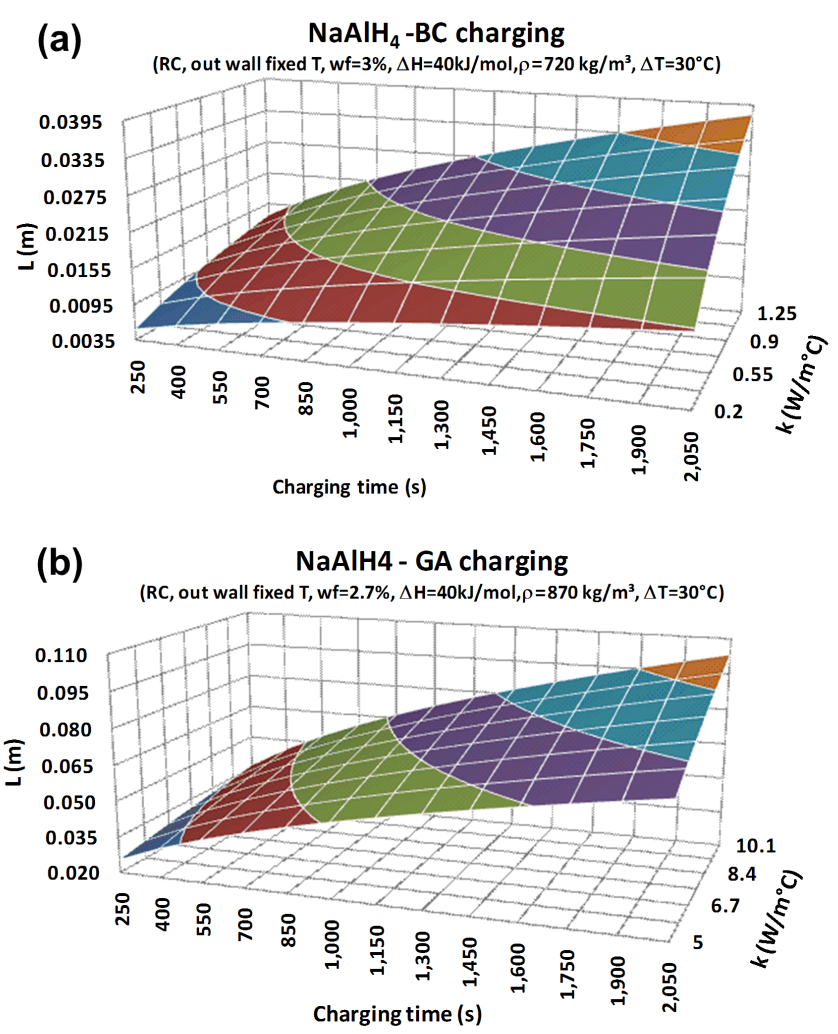

Figure 8. $\mathrm{NaAlH}_{4}$ bed size profile vs charging time and thermal conductivity for rectangular coordinates (RC) and wall fixed temperatures considering the nominal, or baseline material (a) and the graphite added material (b). L represents the distance between the two heat transfer surfaces

Adding graphite to the base form $\mathrm{NaAlH}_{4}$ material causes the thermal conductivity to increase by more than one order of magnitude going from values on the order of $0.3-0.8 \mathrm{~W} / \mathrm{m}-{ }^{\circ} \mathrm{C}$ to values on the order of $8 \mathrm{~W} / \mathrm{m}-{ }^{\circ} \mathrm{C}$ with correspondent density decrease of approximately $20 \%$ and a decrease of wf of approximately $10 \%$. Consequently, as shown in the Figure 8 , the value of $\mathrm{L}$, when graphite is added to the hydride, is approximately 3 times larger than for the unmodified $\mathrm{NaAlH}_{4}$. 


\subsection{2 $\mathrm{LiNH}_{2}: \mathrm{MgH}_{2}$ 1:1 material}

The acceptability envelope model has been applied to a second material, $\mathrm{LiNH}_{2}: \mathrm{MgH}_{2}$ 1:1, assuming the same hypotheses and considerations in Section 4.2. For the unmodified media the values of density (equal to $720 \mathrm{~kg} / \mathrm{m}^{3}$ ), heat of reaction (equal to $40 \mathrm{~kJ} / \mathrm{molH}_{2}$ ), weight fraction wf (equal to $7 \%$ ) and thermal conductivity $(0.3 \mathrm{~W} / \mathrm{m}$ ${ }^{\circ} \mathrm{C}$ ) have been assumed based on recent evaluations and experimental activities [25]. For the modified media in which graphite was added, the data are based on values for modified $\mathrm{NaAlH}_{4}$ case, but wf which is equal to $6.3 \%$..

Figure 9 shows the characteristic spacing of heat transfer surfaces for a $\mathrm{LiNH}_{2}: \mathrm{MgH}_{2}$ 1:1 bed in rectangular coordinate geometry with the temperature fixed at the two surfaces for both the $\mathrm{LiNH}_{2}: \mathrm{MgH}_{2}$ 1:1 - BC case (Figure 9 a) and the $\mathrm{LiNH}_{2}: \mathrm{MgH}_{2}$ 1:1 - GA case (Figure 9 b). 

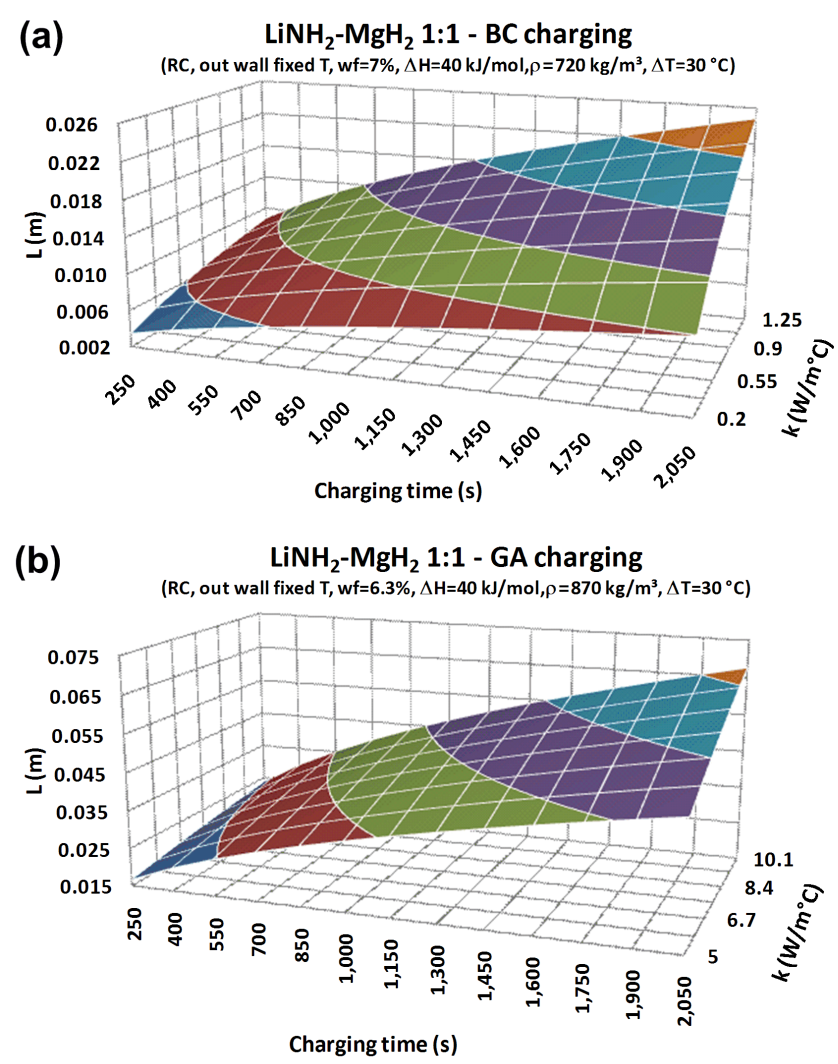

Figure 9. $\quad \mathrm{LiNH}_{2}: \mathrm{MgH}_{2} 1: 1$ bed size profile vs charging time and thermal conductivity for rectangular coordinates (RC) and wall fixed temperatures, considering the nominal or baseline material (a) and the graphite added material (b). L represents the distance between the two heat transfer surfaces

Likewise the $\mathrm{NaAlH}_{4}$ case, adding graphite to the nominal $\mathrm{LiNH}_{2}: \mathrm{MgH}_{2} 1: 1$ material leads to an increase of thermal conductivity of more than one order of magnitude (from $0.3-0.8 \mathrm{~W} / \mathrm{m}-{ }^{\circ} \mathrm{C}$ to approximately $8 \mathrm{~W} / \mathrm{m}-{ }^{\circ} \mathrm{C}$ ). The increased thermal conductivity is accompanied by a density increase on the order of $20 \%$ and a decrease of wf value on the order of $10 \%$. Consequently, the value of $\mathrm{L}$ for the GA case increases by a factor of approximately 3 relative to that for $\mathrm{LiNH}_{2}: \mathrm{MgH}_{2}$ 1:1 - BC. 


\subsection{3 $\mathrm{LiNH}_{2}: \mathrm{MgH}_{2} 2: 1$ material}

The acceptability envelope model has been applied to a third material, $\mathrm{LiNH}_{2}: \mathrm{MgH}_{2}$ 2:1, with the same considerations reported for the previous materials. In particular, the value of heat of reaction (assumed equal to $40 \mathrm{~kJ} / \mathrm{molH}_{2}$ for both $\mathrm{BC}$ and GA material) has been taken from [26], weight fraction wf (4.5\% for BC material and 4.1\% for GA material) from [27]. Thermal conductivity and density have been assumed to have the same values ( $\mathrm{BC}$ and $\mathrm{GA}$ materials) as those for $\mathrm{NaAlH}_{4}$ materials. The maximum temperature difference value within the hydride, $\Delta \mathrm{T}$, during the charging process is based on data from Luo [27] and [25]. In this paper results for $\Delta \mathrm{T}=45^{\circ} \mathrm{C}$ are shown. However, temperature differences ranging from 40 to $50^{\circ} \mathrm{C}$, for rectangular coordinate geometries, were considered. Figure 10 shows the characteristic spacing of heat transfer surfaces for a $\mathrm{LiNH}_{2}: \mathrm{MgH}_{2} 2: 1$ bed in rectangular coordinate geometry with the temperature fixed at both surfaces for the BC case (Figure 10 a) and the GA case (Figure $10 \mathrm{~b}$ ). 

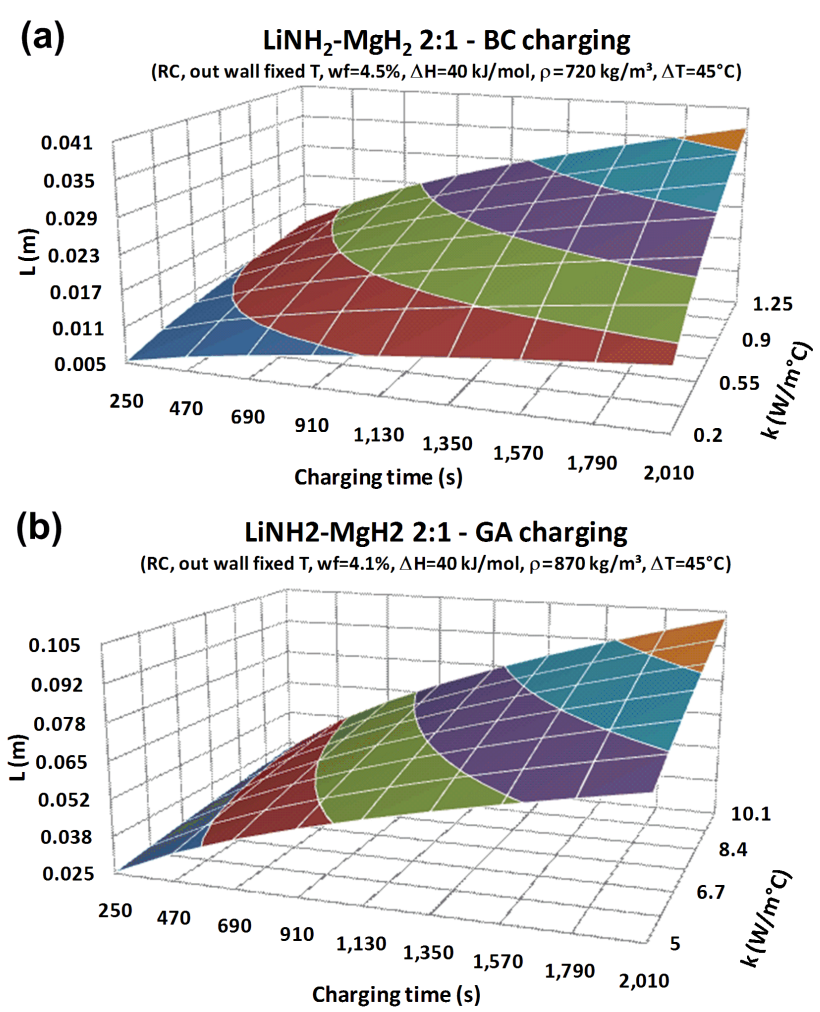

Figure 10. $\quad \mathrm{LiNH}_{2}: \mathrm{MgH}_{2} 2: 1$ bed size profile vs charging time and thermal conductivity for rectangular coordinates (RC) and wall fixed temperatures, considering the nominal or baseline material (a) and the graphite added material (b). L represents the distance between the two heat transfer surfaces

As for $\mathrm{LiNH}_{2}: \mathrm{MgH}_{2}$ 1:1, adding graphite to the nominal $\mathrm{LiNH}_{2}: \mathrm{MgH}_{2} 2: 1$ material increases the thermal conductivity by more than one order of magnitude, from values on the order of $0.3-0.8 \mathrm{~W} / \mathrm{m}-{ }^{\circ} \mathrm{C}$ to values on the order of $8.0 \mathrm{~W} / \mathrm{m}-{ }^{\circ} \mathrm{C}$. The increased thermal conductivity is accompanied by a density increase on the order of $20 \%$ and a decrease of wf value on the order of $10 \%$. Consequently, as shown in Figure 10, the value of $\mathrm{L}$ for $\mathrm{LiNH}_{2}: \mathrm{MgH}_{2} 2: 1$ - GA increases by a factor of approximately 3 relative to that for $\mathrm{LiNH}_{2}: \mathrm{MgH}_{2} 2: 1-\mathrm{BC}$. 


\subsection{4 $\mathrm{MgH}_{2}$ material}

A fourth type of material, $\mathrm{MgH}_{2}$, has been taken into consideration and the acceptability envelope model has been applied. Reference value of heat of reaction (equal to $74 \mathrm{~kJ} / \mathrm{molH}_{2}$ ) for the $\mathrm{BC}$ material has been taken from [28], weight fraction wf for $\mathrm{BC}(7 \%)$ has been taken on the basis of data available from [29], based upon the theoretical capacity equal to $7.6 \%$. Thermal conductivity (equal to $0.2-0.3 \mathrm{~W} / \mathrm{m}-{ }^{\circ} \mathrm{C}$ ) and density $\left(1450 \mathrm{~kg} / \mathrm{m}^{3}\right)$ for the unmodified media have been based on [30] and [31]. The GA case values have been assumed following evaluations carried out for the previous materials. Thus thermal conductivity has been assumed equal to $8.5 \mathrm{~W} / \mathrm{m}-{ }^{\circ} \mathrm{C}$, heat of reaction equal to the $\mathrm{BC}$ case and density and wf equal to $1520 \mathrm{~kg} / \mathrm{m}^{3}$ and $6.3 \%$ respectively, considering the addition of $10 \mathrm{wt} \%$ of graphite to the nominal hydride.

Figures 11 shows profiles of the characteristic spacing of heat transfer surfaces for a base case bed (Figure $11 \mathrm{a}$ ) and for a graphite added bed (Figure $11 \mathrm{~b}$ ) for a rectangular coordinate geometry having the temperature fixed at both surfaces. 

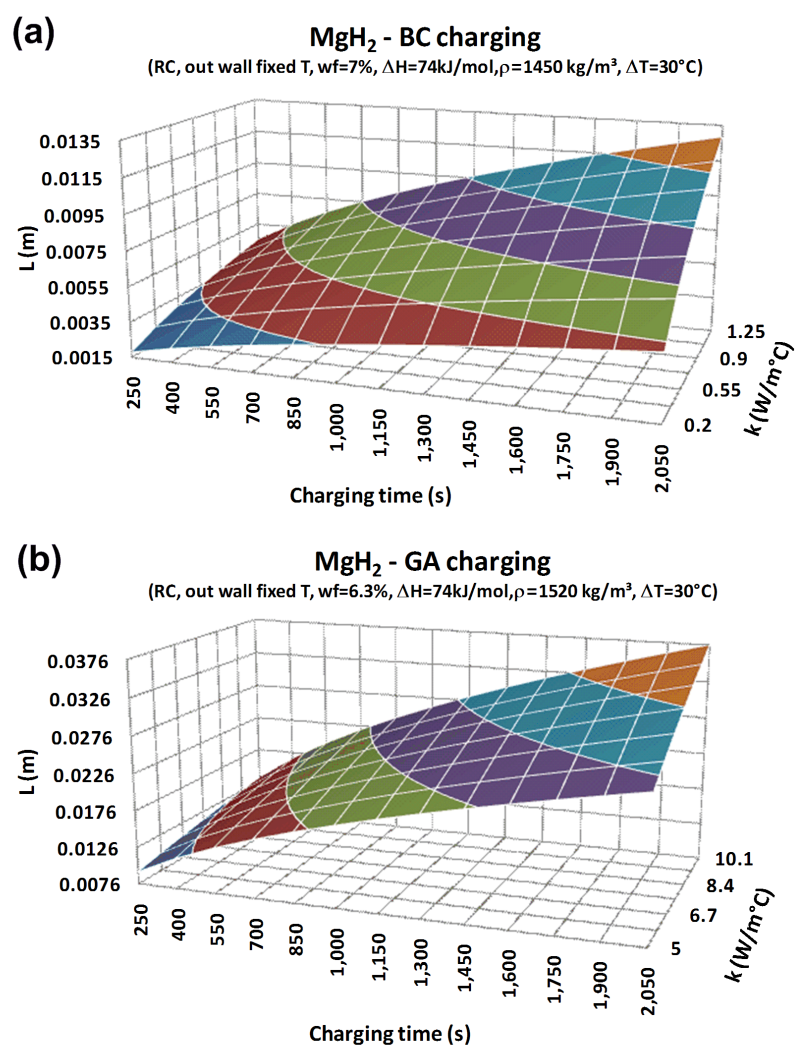

Figure 11. $\mathrm{MgH}_{2}$ bed size profile vs charging time and thermal conductivity for rectangular coordinates (RC) and wall fixed temperatures considering the nominal or baseline material (a) and the graphite added material (b). L represents the distance between the two heat transfer surfaces.

As for $\mathrm{LiNH}_{2}: \mathrm{MgH}_{2} 2: 1$, adding graphite to the nominal $\mathrm{MgH}_{2}$ material was assumed to increase the thermal conductivity by more than one order of magnitude. The increased thermal conductivity is accompanied by a density increase on the order of $5 \%$, because of the high density of the nominal material. As a consequence the spacing of heat transfer surfaces increases by a factor of 3 for the addition of $10 \mathrm{wt} \%$ of graphite.

The present model has been validated by comparison between data reported at [32] and results available from the acceptability envelope applied to $\mathrm{MgH}_{2}$. The system 
analyzed in [32] shows a hydride tank made of $\mathrm{MgH}_{2}$, with natural expanded graphite added at $5 \mathrm{wt} \%$, characterized by the properties described here below. Given the temperature profiles available in the paper [32], a fixed temperature boundary condition can be assumed realistic during the charging time. A hydrogen weight fraction, wf, equal to approximately $5.2 \%$ can be reached in about 35 minutes ( $2100 \mathrm{~s})$. The density of the material is approximately $1100 \mathrm{~kg} / \mathrm{m}^{3}$ [33] with a heat of reaction equal to $75 \mathrm{~kJ} / \mathrm{molH}_{2}$ and a maximum temperature variation, $\Delta \mathrm{T}$, of the order of $18{ }^{\circ} \mathrm{C}$. Thermal conductivity in the radial direction (which is the prevailing heat transfer direction) has been estimated to be equal to $4.2 \mathrm{~W} / \mathrm{m}-{ }^{\circ} \mathrm{C}$ and the value of $\mathrm{L}$ in the same radial direction is approximately $0.027 \mathrm{~m}$ [33]. Results from the acceptability envelope analysis shows $\mathrm{L}$ of the order of $0.027 \mathrm{~m}$ for wf equal to $6.3 \%$, charging time equal to $2050 \mathrm{~s}$ and $\Delta \mathrm{T}$ equal to $30{ }^{\circ} \mathrm{C}, \mathrm{k}$ equal to $5 \mathrm{~W} / \mathrm{m}-{ }^{\circ} \mathrm{C}$, density equal to $1520 \mathrm{~kg} / \mathrm{m}^{3}$ and heat of reaction of $74 \mathrm{~kJ} / \mathrm{molH}_{2}$. Considering Equation 32 and adopting the sensitivity rules reported at the end of Section 2.3, the acceptability envelope $\mathrm{L}$ value for the $\mathrm{MgH}_{2}$ material and vessel coupled system under the conditions of [32] is approximately $0.0254 \mathrm{~m}$. Given the assumptions made to set up the acceptability envelope model which start from a conservative point of view it is possible to conclude that the value is in good agreement with that of [32] for the radial direction.

\subsection{5. $\mathrm{Mg}_{2} \mathrm{NiH}_{4}$ material}

The last type of material taken into consideration is $\mathrm{Mg}_{2} \mathrm{Ni}-\mathrm{H}_{2}$ or $\mathrm{Mg}_{2} \mathrm{NiH}_{4}$. The reference values of heat of reaction $\left(64.5 \mathrm{~kJ} / \mathrm{molH}_{2}\right)$ and weight fraction wf $(3.6 \%)$ for the baseline case have been taken from [34], based upon the theoretical capacity equal to $3.6 \%$. Thermal conductivity $\left(0.3 \mathrm{~W} / \mathrm{m}^{-}{ }^{\circ} \mathrm{C}\right)$ and density $\left(3500 \mathrm{~kg} / \mathrm{m}^{3}\right)$ for the baseline 
case have been assumed based on previous evaluations [25]. The GA case reference values have been assumed in line with evaluations carried out for the previous materials. As a consequence, heat of reaction value is the same of the $\mathrm{BC}$ material, while thermal conductivity has been assumed equal to $8.5 \mathrm{~W} / \mathrm{m}-{ }^{\circ} \mathrm{C}$ and density and wf approximately $3370 \mathrm{~kg} / \mathrm{m}^{3}$ and $3.2 \%$ respectively.

Figure 12 shows the characteristic spacing of heat transfer surfaces for a $\mathrm{Mg}_{2} \mathrm{NiH}_{4}$ bed in rectangular coordinate geometry with the temperature fixed at both surfaces for the BC case (Figure $12 \mathrm{a}$ ) and the GA case (Figure $12 \mathrm{~b}$ ).
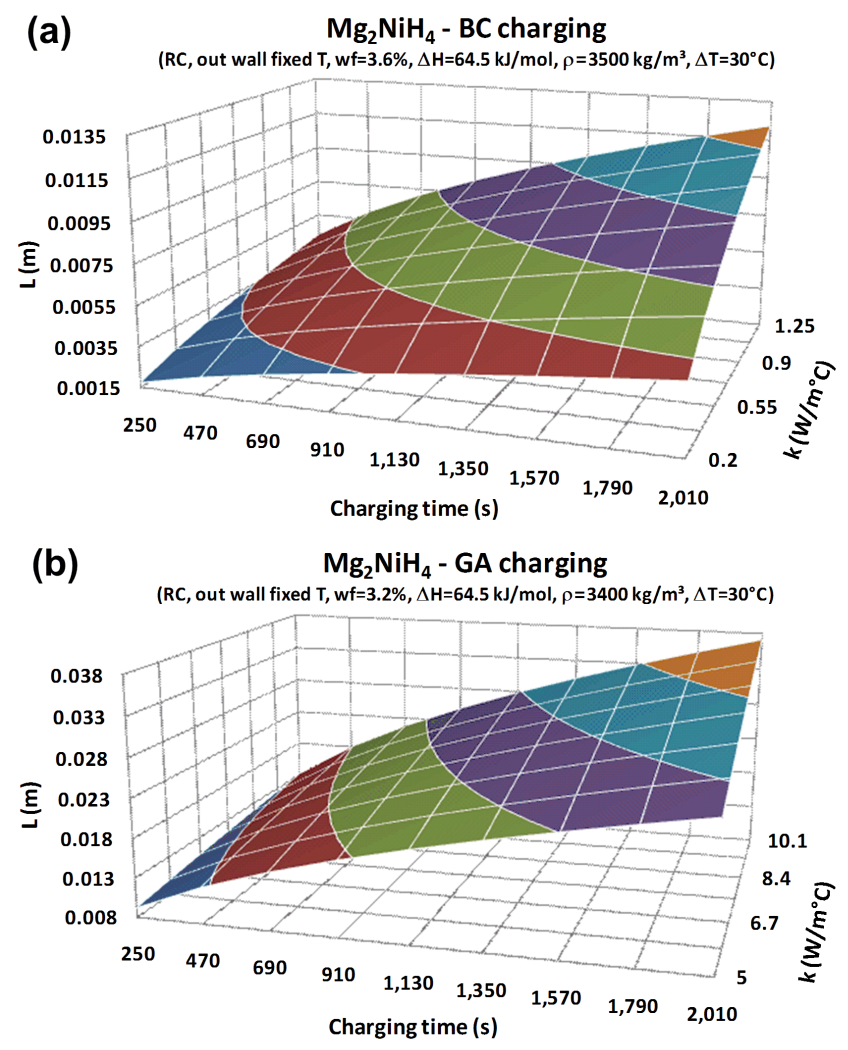

Figure 12. $\mathrm{Mg}_{2} \mathrm{NiH}_{4}$ bed size profile vs charging time and thermal conductivity for rectangular coordinates (RC) and wall fixed temperatures, considering the nominal or baseline material (a) and the graphite added material (b). L represents the distance between the two heat transfer surfaces 
Adding graphite to the nominal $\mathrm{MgH}_{2}$ material increases the thermal conductivity by approximately one order of magnitude. As a consequence the spacing of heat transfer surfaces increases by a factor of 3 for the addition of $10 \mathrm{wt} \%$ of graphite. The increased thermal conductivity is accompanied by a density decrease on the order of $4 \%$ and a decrease in the weight fraction of stored hydrogen, wf, by approximately $10 \%$, assuming the density of nominal $\mathrm{Mg}_{2} \mathrm{NiH}_{4}$ is approximately $3500 \mathrm{~kg} / \mathrm{m}^{3}$.

\subsubsection{Comments and comparisons}

The characteristic spacing of heat transfer surfaces and the hydrogen storage capacities for metal hydrides are compared in Figures 13 and 14, respectively. In Figure 13 the characteristic spacing, L, is for metal hydrides in RC geometry with fixed temperatures at the heat transfer surfaces. The values of $\mathrm{L}$ shown in Figure 13 are for the following conditions:

1. A thermal conductivity $\mathrm{k}$ of $0.7 \mathrm{~W} / \mathrm{m}-{ }^{\circ} \mathrm{C}$ was assumed for the $\mathrm{BC}$ media. Although a nominal thermal conductivity of $0.3 \mathrm{~W} / \mathrm{m}-{ }^{\circ} \mathrm{C}$ was assumed for the storage materials analyzed and compared in this paper, a value equal to $0.7 \mathrm{~W} / \mathrm{m}-{ }^{\circ} \mathrm{C}$ can be assumed to be achieved (based on reasonable future improvements).

2. A value of $8.5 \mathrm{~W} / \mathrm{m}-{ }^{\circ} \mathrm{C}$ was assumed for thermal conductivity when graphite was added to the media at $10 \%$ weight (GA). For this case, as previously stated, the value has been assumed on the basis of activities carried out by General Motors on $\mathrm{NaAlH}_{4}$ material [24]. 
3. Values of $\Delta \mathrm{T}$ equal to $30{ }^{\circ} \mathrm{C}$ and $45{ }^{\circ} \mathrm{C}$ (for $\mathrm{LiNH}_{2}-\mathrm{MgH}_{2} 2: 1$ ) were selected in line with what reported at the previous paragraphs.

4. The filling time was assumed approximately equal to $40 \%$ of the DOE 2010 technical target (about 700 s).

As previously noted, the weight fraction, wf, used in the acceptability envelope is defined as $\mathrm{kg}_{\mathrm{H} 2} / \mathrm{kg}_{\mathrm{Hydride}}$, rather than the system gravimetric capacity (SGC), which is defined as $\mathrm{kg}_{\mathrm{H} 2} / \mathrm{kg}$ Overall System. Thus, to compare the effective storage capacities of the various media to the DOE technical targets, wf must be related to the system gravimetric capacity. A relation between wf and SGC was developed based on data available in literature [21]. From these sources it can be reasonably assumed that the ratio between hydride weight and overall system weight has a value of 0.5 , the same considered for the DOE 2010 case, as reported in Table 3.

The system gravimetric capacity, SGC in percentage, is $1.8 \%$ at $40 \%$ of the gravimetric capacity given for the 2010 DOE technical target. For the assumed value of the ratio between hydride and system weight, the value of wf must be greater than or equal to $0.036(=0.018 / 0.5)$ to meet this target. Thus, the wf\% target of 3.6 is used as the goal in Figure 14. Such a figure shows percent weight fraction, wf\%, values for both unmodified (BC) and modified (GA, assuming the addition of $10 \mathrm{wt} \%$ graphite) cases. The wf\% loadings for each metal hydride in Figure 14 are based on a loading time corresponding to $40 \%$ of the DOE 2010 loading rate required to store $5 \mathrm{~kg}$ of hydrogen.

Based upon engineering judgment the characteristic spacing of heat transfer surfaces, L, for RC geometry and fixed temperatures at the heat transfer surfaces, must be greater than $0.022-0.025 \mathrm{~m}$ for the assumed value of the ratio between hydride and 
system weight. Otherwise, for lower values of $\mathrm{L}$, the value of the weight ratio between hydride and overall system decreases below 0.5 and, consequently, the value of wf\% required to meet the DOE 2010 targets increases above 3.6. Values of L required for metal hydrides to meet $40 \%$ of the $2010 \mathrm{DOE}$ charging rate target, for RC geometry with fixed temperatures at the heat transfer surfaces, are shown in Figure 13.

Based on the results shown in Figures 13 and 14, under the conditions set in the present work, the most promising of the metal hydrides considered in this document, seem to be those based on $\mathrm{Li}$ and $\mathrm{Mg}$.

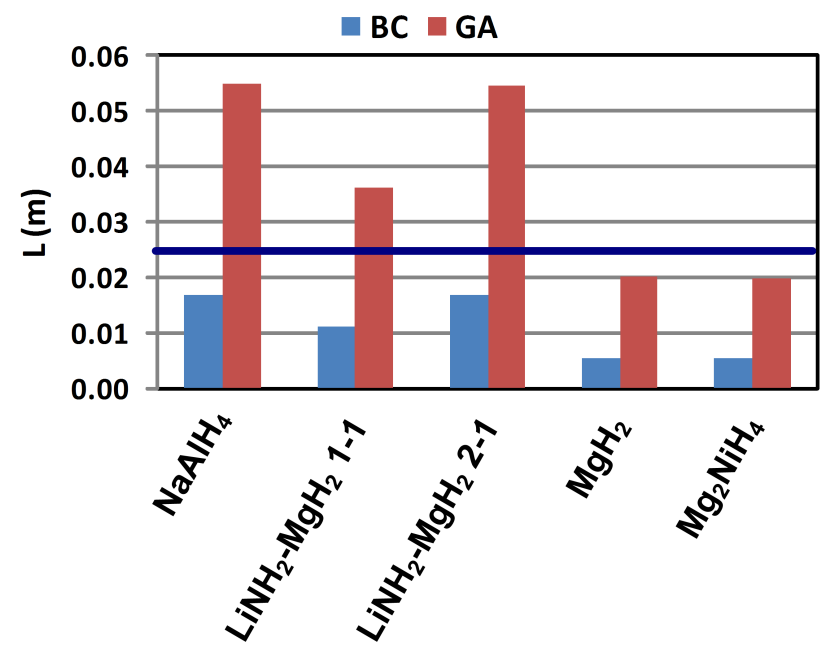

Figure 13. Characteristic spacing between heat transfer surfaces, L, in rectangular coordinate geometry and fixed temperatures at the heat transfer surfaces, required to meet $40 \%$ of the 2010 DOE loading rate targets. Values of $\mathrm{L}$ are shown for the nominal, base case (BC) metal hydrides and for metal hydrides with the addition of 10 $\mathrm{wt} \%$ graphite (GA). Based on engineering judgment, L must be greater than $0.022-0.025 \mathrm{~m}$ to meet the DOE technical targets. 


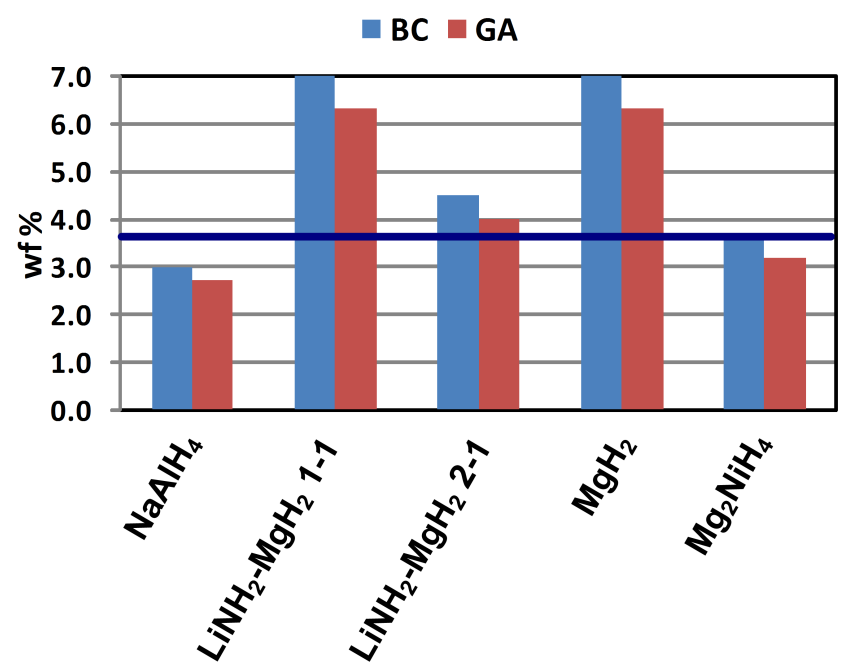

Figure 14. Weight fraction hydrogen storage, wf $\%$, in terms of $\mathrm{kg}_{\mathrm{H} 2} / \mathrm{kg}_{\mathrm{Hydride}}$ * 100 , for the nominal, base case (BC) metal hydrides, and for metal hydrides with addition of $10 \mathrm{wt} \%$ graphite (GA). To meet the 2010 DOE targets $\mathrm{wf} \%$ must be greater than 3.6.

\section{Conclusions}

A general scoping methodology, called the Acceptability Envelope Analysis, was developed to identify the range of parameters that allow a coupled media and storage vessel system to meet performance targets.

The model, developed to carry out the analysis, reduced the system to a simple one input-one output linear scheme, by parameter grouping. By this approach the bed storage system model was made very flexible and straightforward and, in general, each parameter could be assumed as the output of the model.

In this paper the acceptability envelope was developed for, and applied to, metal hydride based storage systems to determine media and system parameters required to meet determined technical targets. 
In particular, the acceptability envelope analysis was applied to two different scenarios. In the first case, it was applied to metal hydride based storage systems to determine media and system parameters required to meet the DOE technical targets for Year 2010, Year 2015, and the DOE Ultimate targets.

In the second case, some of the properties of various candidate media were assumed and the methodology was used to find the values of media parameters and heat transfer surface spacing that permit a storage system to meet the DOE technical targets. Additionally, the thermal conductivity (a media property) was increased via the addition of graphite and the impact of this property modification on values of characteristic parameters required for the storage system to meet the technical targets was examined. In this case the acceptability envelope was used as a preliminary screening material tool, giving an idea of the actual system size needed to reach the given targets. The analysis showed that the addition of graphite to the base material allows an increase of the spacing between heat transfer surfaces of approximately 3 times related to the nominal material with noticeable improvements in term of system gravimetric capacity. On the other hand, for all the materials, a reduction of wf on the order of $10 \%$ was observed. Consequently, given the assumptions of the present work, among the selected materials, the Li-Mg based ones showed the best potential to achieve the $40 \%$ of the 2010 DOE target in terms of system gravimetric capacity.

\section{Acknowledgements}

This work was performed as part of the DOE Hydrogen Storage Engineering Center of Excellence (HSECoE); with the support of the U.S. Department of Energy gratefully acknowledged. The authors also wish to thank Drs. T. Motyka (Savannah 
River National Laboratory) and N. Stetson (U.S. Department of Energy) specifically for their useful suggestions.

\section{References}

1. Gardiner M. Energy requirements for hydrogen gas compression and liquefaction as related to vehicle storage needs. DOE Hydrogen Program Record, Record \# 9013, (2009).

2. DOE Hydrogen Storage Website, http://www.eere.energy.gov/hydrogenandfuelcells/storage/hydrogen_storage_testing.html

3. Syed MT, Sherif SA, Veziroglu TN, Sheffield JW. An economic analysis of three hydrogen liquefaction systems. Int J Hydrogen Energy 1998;23(7):565-576 .

4. Hardy BJ, Anton DL. Hierarchical methodology for modeling hydrogen storage systems. Part I: Scoping models. Int J Hydrogen Energy 2009;(34):2269-2277.

5. Aldas K, Mat M, Kaplan Y. A three-dimensional model for absorption of hydrogen in a metal hydride bed. Int J Hydrogen Energy 2002;10(27):1049-1056.

6. Anton DL, Mosher DA. High density hydrogen storage system demonstration using NaAlH4 complex compound hydride. Proceedings of the DOE hydrogen program 2005 Annual Merit Review. Arlington, VA; May 23-26, 2005

7. Askri F, Jemni A, Nasrallah SB. Prediction of transient heat and mass transfer in a closed metal-hydrogen reactor. Int J Hydrogen Energy 2004;29:195-208. 
8. El-Osairy MA, El-Osery IA, Metwally AM, Keshk MM. Temperature and composition analysis of a convective model of metal hydride hydrogen storage beds. Int J Hydrogen Energy 1992a; 2(17):125-128.

9. El-Osairy MA, El-Osery IA, Metwally AM, Keshk MM. On the optimization of convective hydrogen storage bed model using LaNi5H6 or FeTiH1.6. Int J Hydrogen Energy 1992b;17(17):961-964.

10. Georgiadis MC, Kikkinides ES, Makridis SS, Kouramas K, Pistikopoulos EN. Design and optimization of advanced materials and processes for efficient hydrogen storage. Computers Chem Eng 2009;33(5):1077-1090.

11. Hardy BJ, Anton DL. Hierarchical methodology for modeling hydrogen storage systems. Part II: Detailed models. Int J Hydrogen Energy 2009;(34):2992-3004.

12. Jemni A, Nasrallah B, Lamloumi, J. Experimental and theoretical study of a metal-hydrogen reactor. Int J Hydrogen Energy 1999;24:631.

13. Mellouli S, Askri F, Dhaou H, Jemni A, Ben Nasrallah S. Numerical simulation of heat and mass transfer in metal hydride hydrogen storage tanks for fuel cell vehicles. Int J Hydrogen Energy 2010;35(4):1693-1705.

14. Mosher D, Tang X, Arsenault S, Laube B, Cao M, Brown R, et al. High density hydrogen storage system demonstration using NaAlH4 complex compound hydrides. Proceedings of the DOE hydrogen program 2007 Annual Merit Review. Washington, DC; May 15-18, 2007. 
15. Kikkinides ES, Georgiadis MC, Stubos AK. On the optimization of the storage in metal hydride beds. Int J Hydrogen Energy 2006;31:737-751.

16. Krokos CA, Nikolic D, Kikkinides ES, Georgiadis MC, Stubos AK. Modeling and optimization of multi-tubular metal hydride beds for efficient hydrogen storage. Int J Hydrogen Energy 2009;34:9128-9140.

17. Wang Y, Adroher XC, Chen J, Yang XG, Miller T. Three-dimensional modeling of hydrogen sorption in metal hydride hydrogen storage beds. Journal of Power Sources 2009;194:997-1006

18. Dhaou H, Askri F, Ben Salah M, Jemni A, Ben Nasrallah S, Lamloumi J. Measurement and modeling okinetics of hydrogen sorption by $\mathrm{LaNi}_{5}$ and two related pseudobinary compounds. Int J Hydrogen Energy 2007;32:576-587.

19. MacDonald BD, Rowe AM. A thermally coupled metal hydride hydrogen storage and fuel cell system. Journal of Power Sources 2006;161(1):346-355

20. US Department of Energy Office of Energy Efficiency and Renewable Energy and The FreedomCAR and Fuel Partnership. Targets for Onboard Hydrogen Storage Systems for Light-Duty Vehicles. September 2009. Available at https://www1.eere.energy.gov/hydrogenandfuelcells/storage/pdfs/targets_onboard_hydro _storage_explanation.pdf

21. Mosher DA, Tang X, Brown RJ, Arsenault S, Saitta S, Laube BL, et al. High Density Hydrogen Storage System Demonstration Using NaAlH4 Based Complex 
Compound Hydrides. Final Report, DOE Hydrogen Program-H2 Storage, Contract DEFC36-02AL67610, July 272007.

22. Garrison SL, Gorbounov MB, Tamburello DA, Hardy B, Corgnale C, Mosher D, et al. Automatic Optimization of Metal Hydride Storage Tanks and Novel Designs. Proceedings of AIChE 2010 Annual Meeting, Salt Lake City, USA, 2010.

23. Hardy BJ. Geometry Heat Removal and Kinetics Scoping Models for Hydrogen Storage Systems. WSRC-TR-2007-00439 Report, Savannah River National Laboratory, 2007.

24. Kumar D, Mandhapati R, Kumar S. On-Board Hydrogen Storage Systems Simulation Models And System Performance. HSECoE Face To Face 4th Meeting, March 2-4, 2010.

25. Motyka T, Garrison S. Personal communications. Savannah River National Laboratory; 2010.

26. Barison S, Agresti F, Lo Russo S, Maddalena A, Palade P, Principi G, et al. A study of the LiNH2-MgH2 system for solid state hydrogen storage. Journal of Alloys and Compounds 2008;459:343-347.

27. Luo W. (LiNH2-MgH2): a viable hydrogen storage system. Journal of Alloys and Compounds 2004;381:284-287.

28. Bogdanovic B, Bohmhammel K, Christ B, Reiser A, Schlichte K, Vehlen R, et al. Thermodynamic investigation of the magnesium-hydrogen system. Journal of Alloys and Compounds 1999;282:84-92. 
29. Huot J, Liang G, Boily S, Van Neste A, Schulz R, et al. Structural study and hydrogen sorption kinetics of ball-milled magnesium hydride. Journal of Alloys and Compounds 1999;293:495-500.

30. Chaise A, de Rango P, Marty P, Fruchart D, Miraglia S, Olives R, et al. Enhancement of hydrogen sorption in magnesium hydride using expanded natural graphite. Int J Hydrogen Energy 2009;34:8589-8596.

31. Kapischke J, Hapke J. Measurement of the effective thermal conductivity of a $\mathrm{Mg}-\mathrm{MgH} 2$ packed bed with oscillating heating. Experimental Thermal and Fluid Science 1998;17(4):347-355.

32. Chaise A, de Rango P, Marty P, Fruchart D. Experimental and numerical study of a magnesium hydride tank. Int J Hydrogen Energy 2010;35:6311-6322.

33. Marty P. Personal communications. Commisariat a l'Energie Atomique (CEA), France, 2011.

34. DOE Sandia National Laboratory Metal Hydride Properties Database http:/hydpark.ca.sandia.gov/PropertiesFrame.html. 